Saliba, N. and Gardner, L. (2013). Cross-section stability of lean duplex stainless steel welded I-sections. Journal of Constructional Steel Research. 80(1), 1-14.

\title{
Cross-section stability of lean duplex stainless steel welded I-sections
}

\author{
N. Saliba ${ }^{1}$ and L. Gardner ${ }^{1}$ \\ ${ }^{1}$ Department of Civil and Environmental Engineering, Imperial College London, London, SW7 2AZ, \\ UK. \\ Corresponding author: Prof Leroy Gardner, Department of Civil and Environmental Engineering, \\ Imperial College London, London, SW7 2AZ, UK. Email: Leroy.gardner@imperial.ac.uk
}

\begin{abstract}
Despite growing interest in the use of stainless steel in construction and the development of a number of national and regional design codes, stainless steel is often still regarded as only suitable for specialised applications. This is partly due to the high initial material cost associated with the most commonly adopted austenitic grades. The initial material cost of stainless steel is largely controlled by the alloy content, in particular the level of nickel, which is around $8 \%-10 \%$ for the common austenitic grades. A recently developed grade, known as lean duplex stainless steel (EN 1.4162), has a far lower nickel content, around 1.5\%, and hence lower cost. Despite the low nickel content, it possesses higher strength than the common austenitic stainless steels, along with good corrosion resistance and high temperature properties and adequate weldability and fracture toughness. The structural performance of lean duplex stainless steel remains relatively unexplored to date with only a few studies having been performed. For this reason, an experimental and analytical research programme investigating the structural characteristics of lean duplex stainless steel was initiated. The present paper summarizes the laboratory tests performed on lean duplex stainless steel welded I-sections. The experiments include material testing, stub column tests and 3-point and 4-point bending tests. The experimental data were supplemented by results generated by means of a comprehensive numerical investigation including parametric studies covering a wide range of cross-sections. The obtained experimental and
\end{abstract}


numerical results, together with the results of previous tests performed on lean duplex stainless steel cold-formed hollow sections are reported and used to assess the applicability of existing cross-section classification limits and the continuous strength method (CSM) to lean duplex stainless steel. Furthermore, the structural performance of lean duplex stainless steel was compared to the more commonly used stainless steel grades. Finally, based on the obtained results, design recommendations suitable for incorporation into Eurocode 3: Part 1.4 are proposed.

Keywords: Bending, Compression, Cross-section classification, Experiments, Finite element, Lean Duplex, Numerical modelling, Stainless steel, Structural testing, Stub columns, Welded I-sections,.

\section{Introduction}

The initial material cost of stainless steel is sensitive to the alloy content, in particular the level of nickel. For the most commonly adopted family of stainless steels - the austenitics - the nickel content is between about $8 \%$ and $10 \%$ by weight. A recently developed grade of stainless steel, known as lean duplex (EN 1.4162), has a far lower nickel content, around 1.5\% [1], and hence considerably reduced cost. Despite the low nickel content, it possesses higher strength than austenitic stainless steel, along with good corrosion resistance and high temperature properties, and adequate weldability and fracture toughness [2-4].

Lean duplex stainless steel is not currently covered by any structural design code owing to its recent introduction and the present lack of structural performance data, though it is included in the material standard EN 10088-4 [1], with a minimum specified $0.2 \%$ proof strength of $480 \mathrm{~N} / \mathrm{mm}^{2}$ for plate material in the annealed condition. For this reason, a comprehensive experimental and numerical research programme investigating the structural characteristics of lean duplex stainless steel welded Isections was initiated at Imperial College London. The experiments include material testing, stub column tests and 3-point and 4-point bending tests, with a focus on characterising the basic material properties and establishing slenderness limits for cross-section classification. The experimental study was complemented by a parallel 
numerical investigation, in which finite element models were initially validated against the test results and subsequently used for parametric studies.

The obtained experimental and numerical results are carefully reported and used, together with existing test data $[5,6]$ to assess the applicability of the codified slenderness limits employed in Eurocode 3: Part 1.4 [7] and the application of the continuous strength method (CSM) $[8,9]$. Furthermore, the results obtained from lean duplex stainless steel tests are compared to the results of tests performed on other stainless steel grades. Finally, based on the obtained results, design recommendations are made.

\section{Experimental investigation}

\subsection{Material properties}

In order to obtain the basic stress-strain properties of the lean duplex material, a series of tensile and compressive coupon tests were performed in the Structures Laboratory of the Department of the Civil and Environmental Engineering at Imperial College London on material extracted from the plate material used to form the structural crosssections. A total of twenty-four coupons of four material thicknesses $(6 \mathrm{~mm}, 8 \mathrm{~mm}, 10$ $\mathrm{mm}$, and $12 \mathrm{~mm}$ ) were tested in tension and compression. For each thickness, two repeated tensile tests were carried out on longitudinal coupons (i.e. parallel to the rolling direction). For the compression coupons, two repeated tests on both longitudinal and transverse (i.e. perpendicular to the rolling direction) coupons were carried out for each thickness. The tests followed the provisions of EN 10002-1 [10]. The nominal dimensions of the necked tensile coupons were $320 \times 30 \mathrm{~mm}$ while the nominal dimensions for the compressive coupons were $72 \times 16 \mathrm{~mm}$. The tests were carried out in an INSTRON $250 \mathrm{kN}$ machine with an initial strain rate of $0.0003 \mathrm{~s}^{-1}$, increasing after $1 \%$ strain to a strain rate of $0.008 \mathrm{~s}^{-1}$. The tensile coupons were marked with proportional gauge lengths to calculate their plastic strain at fracture $\varepsilon_{\mathrm{f}}$ after testing, based on elongation over the standard gauge length $5.65 \sqrt{\mathrm{A}_{c}}$ where $A_{c}$ is the crosssectional area of the coupon. Tensile strain was measured by means of a digital extensometer. The compressive coupons were tested in a bracing jig to prevent 
buckling; strain gauges were attached to both sides of the tested coupons at mid height. All test data, including load, displacement, strain and input voltage were recorded at one-second intervals using the data acquisition system DATASCAN. The key results from the coupon tests, together with the mill certificate material properties, are summarised in Tables 1 and 2, where E is Young's modulus, $\sigma_{0.2}$ is the $0.2 \%$ proof stress, $\sigma_{1.0}$ is the $1.0 \%$ proof stress, $\sigma_{\mathrm{u}}$ is the ultimate tensile stress, $\varepsilon_{\mathrm{f}}$ is the plastic strain at fracture based on elongation over the standard gauge length and $\mathrm{n}$ and n', ${ }_{0.2,1.0}$ are strain hardening exponents for the compound Ramberg-Osgood model [11, 12] as modified by Gardner and Ashraf [13]. The stress-strain curves for each of the tested thicknesses are presented in Figs 1-8.

The similarity of results obtained from the tensile and compressive coupons tests carried in the longitudinal direction, indicated essentially symmetric stress-strain characteristics. For compressive properties, coupon tests were conducted in both the longitudinal and transverse directions. The results indicated anisotropic behaviour, with the strength in the transverse direction being consistently higher than that in the longitudinal direction. This anisotropy has been observed in previous studies of duplex stainless steel [14], and is associated with elongation in the rolling direction of the crystalline grains in the microstructures. The measured $0.2 \%$ proof stresses from the longitudinal coupon tests were found to be lower than those stated in the mill certificates - this may be attributed to the difference in testing direction and higher strain rates typically employed in mill tests. The results obtained from the compressive coupon tests in the transverse direction, which have been observed to be similar to the transverse tensile properties in previous studies [15], were generally in a good agreement with those given in the mill certificates. The mean measured values of the Ramberg-Osgood $\mathrm{n}$ and $\mathrm{n}_{0.2,1.0}$ parameters for the tested plate material were 10.0 and 2.0 respectively with some variation depending on rolling and loading direction; this compares to corresponding values of 7.0 and 3.3 for cold-formed lean duplex stainless steel hollow sections $[5,6]$, which indicate that the cold-formed material has a more rounded stress-strain response.

\subsection{Measurement of geometric imperfections}


The basic geometry of the lean duplex stainless steel welded I-section test specimens was measured prior to testing. The key measurements are summarised in Sections 2.3 and 2.4. Local geometric imperfections were also measured prior to testing, following the method adopted by Schafer and Peköz [16]. Each section was placed on the flat surface of a milling machine and a linear variable displacement transducer (LVDT) held in the head of the milling machine was run along the centreline of the web and the tips of the flanges over a measurement zone spanning the central half of the specimens' lengths. The maximum measured local geometric imperfection $\left(\omega_{\text {flange } 1}, \omega_{\text {flange2, }} \omega_{\text {web }}\right)$, defined as the maximum deviation from a straight line connecting to two ends of the measurement zone, for each of the sections is given in Table 3. The obtained imperfections were employed in the numerical study described in Section 3 of this paper.

\subsection{Stub column tests}

Four stub columns were tested under pure axial compression. The nominal length of the stub columns was selected as three times the larger cross-section dimension and less than 20 times the radius of gyration [17] in order to avoid overall buckling but to still include a representative distribution of geometric imperfections and residual stresses. The ends of each specimen were machined flat and square to ensure a uniform distribution of loading during testing and were compressed between the parallel platens of the testing machine, as shown in Fig. 9. The instrumentation consisted of one LVDT used to measure the end shortening, a load cell to record the applied load and four strain gauges located at the mid heights of the flanges which were used to confirm that the load was being applied concentrically and to eliminate elastic deformations of the platens from the end shortening readings, as described later. The tests were carried out in an INSTRON $3500 \mathrm{kN}$ machine under displacement-control at a rate of $0.3 \mathrm{~mm} / \mathrm{min}$. Results, including load, displacements, strain and input voltage were all recorded at one-second intervals using the data acquisitions system DATASCAN. Tests were continued beyond the ultimate load-carrying capacity of the stub columns, and the postultimate response was recorded. The geometric properties of the stub columns (see Fig. 10) and the key test results are summarised in Table 4, where $L$ is the specimen length, $b$ is the overall flange width, $h_{w}$ is the web depth, $t_{f}$ is the thickness of the flange, $t_{w}$ is the thickness of the web, $\mathrm{A}$ is the gross cross-sectional area and $\mathrm{N}_{\mathrm{u}}$ is the ultimate load 
achieved by the stub columns. The employed specimen designation system begins with section type, followed by section depth $\times$ flange width $\times$ flange thickness $\times$ web thickness. All specimens failed by local buckling, a typical example of which can be seen in Fig. 11. The measured load-end shortening curves are shown in Fig. 12. Following the approach set out in [18], the true end shortening of the stub columns, excluding the deformation of the endplatens, were determined; all results shown herein are presented on this basis.

\subsection{Beam tests}

A total of eight welded I-sections were tested in bending - four in a 3-point configuration and four in a 4-point configuration. The tests were used to assess bending resistance and rotation capacity and to determine the applicability of the European codified slenderness limits and other proposed bases of design to lean duplex stainless steel. Each specimen was a total of $3000 \mathrm{~mm}$ in length, simply supported between two steel rollers placed $100 \mathrm{~mm}$ inwards from the ends of the beams. Lateral restraints were provided at the load points and supports to prevent lateral torsional buckling. The

generalized member slenderness $\bar{\lambda}_{\text {LT }}$ for the welded I-sections defined in [7] varied between 0.29 and 0.34, which is lower than the Eurocode 3: Part 1.4 [7] limit of 0.4 below which lateral torsional buckling may be ignored. For the 3-point bending tests, the load was applied at mid-span while for the 4-point bending tests, the load was applied at two points (900 mm from each support), as shown in Figs 13 and 14, respectively. For each of the tested beams, web stiffeners were provided at both the end supports and the positions of the applied loads. Strain gauges were attached to the top and bottom flanges of each specimen at a distance of $100 \mathrm{~mm}$ from the mid-span in order to monitor the progression of strain during testing. Inclinometers were placed at each end of the beam in order to determine the rotation of the beams at the support points. For the 3-point bending configuration, one Linear Variable Displacement Transducer (LVDT) was attached to the centre of the bottom flange to measure the displacement of the beam, while for the 4-point bending configuration, three LVDTs were attached to the bottom flange: one at the mid-span of the beam and the other two below the load points (i.e. $900 \mathrm{~mm}$ from each support). Furthermore, four string 
potentiometers were attached to the beams, two at each end, in order to measure the longitudinal displacement of the beams. The tests were carried out in an INSTRON $2000 \mathrm{kN}$ machine and displacement-controlled at a rate of $3.0 \mathrm{~mm} / \mathrm{min}$. Loads, rotations, displacements and strains were all recorded at one-second intervals using the data acquisition system DATASCAN.

The failure modes of the beams in both the 3-point and 4-point bending tests, exhibiting local buckling of the compression flange, are shown in Figs 15 and 16 respectively. The section dimensions and key experimental results from the beam tests are summarised in Tables 5-8. The obtained mid-span moment rotation and moment-curvature curves from the 3-point and 4-point bending tests, respectively, are shown in Figs 17 and 18, where $M_{u}$ is the ultimate test moment, $M_{e l}$ is the elastic moment capacity, $M_{p l}$ is the plastic moment capacity, $\theta$ is the rotation at mid-span taken as the sum of the end rotations, $\theta_{\mathrm{u}}$ is the total rotation at mid-span when the moment curve falls back below $\mathrm{M}_{\mathrm{pl}}$ as obtained from the test results, $\theta_{\mathrm{pl}}$ is the elastic component of the rotation when $\mathrm{M}_{\mathrm{pl}}$ is reached defined as $\theta_{\mathrm{pl}}=\mathrm{M}_{\mathrm{pl}} \mathrm{L} / 2 \mathrm{EI}$ where $\mathrm{I}$ is the second moment of area of the section, $\kappa$ is the curvature, $\kappa_{\mathrm{u}}$ is the total curvature at the plastic hinge when the momentrotation curve falls back below $\mathrm{M}_{\mathrm{pl}}$, and $\kappa_{\mathrm{pl}}$ is the elastic curvature corresponding to $\mathrm{M}_{\mathrm{pl}}$ defined as $\kappa_{\mathrm{pl}}=\mathrm{M}_{\mathrm{pl}} / \mathrm{EI}$. The elastic and plastic moment capacities $\mathrm{M}_{\mathrm{el}}$ and $\mathrm{M}_{\mathrm{pl}}$ were calculated by multiplying the relevant measured section modulus with the weighted average tensile $0.2 \%$ proof stress of the section. The rotation capacity $\mathrm{R}$ was calculated using equations (1) and (2)

$$
\begin{aligned}
& \mathrm{R}=\frac{\theta_{\mathrm{u}}}{\theta_{\mathrm{pl}}}-1 \\
& \mathrm{R}=\frac{\kappa_{\mathrm{u}}}{\kappa_{\mathrm{pl}}}-1
\end{aligned}
$$

The results of the experiments are employed for the validation of the numerical models in Section 3 of this paper and are analysed and discussed in Section 4.

\section{Numerical modelling}

\subsection{Introduction}


A numerical study using the general-purpose finite element analysis package ABAQUS [19] was conducted in parallel with the testing programme. Initially, the experimental results reported in Section 2 were used to validate the FE models. The validated FE models were subsequently used for parametric studies to assess the influence of key parameters on the structural response of lean duplex stainless steel cross-sections over a wide range of slendernesses.

\subsection{Basic modelling assumptions}

The finite element type S4R, a four-noded doubly curved general-purpose shell element with reduced integration and finite membrane strains, selected from the ABAQUS [19] element library, was used throughout the study. This element is suited to the modeling of a range of shell thicknesses and hence cross-section slendernesses, and has been successfully employed in a number of previous studies such as those reported by Ellobody and Young [20] and Lecce and Rasmussen [21].

Measured geometric and material properties, as obtained from the experimental investigation, were carefully incorporated into the numerical models. The material properties adopted for the stub column models were the average of those obtained from the two longitudinal compressive coupon tests for each material thickness. For the 3point and 4-point bending models, the average stress-strain response of the two tensile coupons for each thickness were applied to the lower halves of the beams, while the average of the two longitudinal and two transverse compressive coupons were applied to the upper halves. Boundary conditions were carefully selected to mimic the experimental setups. For the stub column, all degrees of freedom were restrained at the two end cross-sections of the models apart from vertical translation at the loaded end to allow for vertical displacement. For the 3-point and 4-point bending models, vertical displacement was restrained at the ends of the beams, while lateral displacement was prevented at the positions of the lateral restraints. Longitudinal displacement was prevented at the mid-spans of the beams.

\subsection{Material modelling}


Numerous material models have been applied to represent the nonlinear stress-strain relationship of stainless steel, the most popular being the basic Ramberg-Osgood model $[22,23]$ or variations thereof $[11-13,24,25]$. In the present study, the two-stage Ramberg-Osgood model described by Gardner and Ashraf [13] was employed to represent the stress-strain response of stainless steel; for incorporation into ABAQUS, this was approximated with a multi-linear model defined in terms of true stress and log plastic strain. The relationship between true stress and engineering stress, $\sigma_{\text {true }}$ and $\sigma_{\text {nom }}$, respectively, is given by Eq. (3), while the relationship between log plastic strain and engineering strain, $\varepsilon_{1 \mathrm{n}}^{\mathrm{pl}}$ and $\varepsilon_{\text {nom }}$, respectively is given by Eq. (4), where $\sigma_{\text {nom }}$ and $\varepsilon_{\text {nom }}$ are the engineering stress and strain respectively and E is the Young's modulus.

$$
\begin{aligned}
& \sigma_{\text {true }}=\sigma_{\text {nom }}\left(1+\varepsilon_{\text {nom }}\right) \\
& \varepsilon_{\ln }^{\mathrm{pl}}=\ln \left(1+\varepsilon_{\text {nom }}\right)-\frac{\sigma_{\text {true }}}{E}
\end{aligned}
$$

\subsection{Initial geometric imperfections}

All structural elements contain initial geometric imperfections, which arise principally during production and fabrication stages. These imperfections can significantly influence the structural behaviour; hence, it is necessary to account for imperfections in any numerical modelling investigation. The method adopted in the present study to account for initial geometric imperfections was to first perform an elastic buckling analysis to determine the lowest relevant elastic buckling mode shape, and then to use this mode shape, with a chosen amplitude, as the initial geometric imperfection in a subsequent nonlinear analysis. The nonlinear analysis was performed using the modified Riks methods [19], which is an algorithm that enables effective solutions to be found to unstable problems (e.g., post ultimate response of stub columns) and adequately traces nonlinear unloading paths. Four imperfection amplitudes were considered: (1) the maximum measured imperfection $\omega_{0}$ from the laboratory, (2) $t / 100$, where $t$ is the thickness of the web for the stub column tests and the thickness of the flanges for the 3-point and 4-point beam tests (since these were the critical (i.e. most slender) elements in each case), (3) t/1000 and (4) the imperfection amplitude $\omega_{\mathrm{D} \& \mathrm{~W}}$ derived from the predictive model of Dawson and Walker [26] as modified by Gardner and Nethercot [27] defined by Eq. (5), 
$\omega_{\mathrm{D \& W}}=0.023\left(\sigma_{0.2} / \sigma_{\mathrm{cr}}\right) \mathrm{t}$

where $\sigma_{0.2}$ is the tensile $0.2 \%$ proof stress and $\sigma_{\mathrm{cr}}$ is the elastic critical buckling stress of the most slender constituent plate element in the section, determined on the basis of the flat width of the element. Note that only local imperfections were considered in the models, since global buckling was prevented.

\subsection{Residual stresses}

Residual stresses are those that exist within a structural member in its unloaded state. Similarly to initial geometric imperfections, they originate primarily during production and fabrication processes. The general influence of residual stresses on structural members is to cause premature yielding and loss of stiffness, which can significantly deteriorate load carrying capacity. The physical and thermal properties of stainless steel differ from those of carbon steel, hence residual stress patterns and magnitudes arising in structural sections may differ [28]. A number of studies have involved the examination of residual stresses in cold-formed stainless steel sections [29-34] whilst fewer have addressed welded stainless steel sections [35, 36]. The studies of Lagerqvist and Olsson [35] and Bredenkamp et al. [36] focused on welded I-sections, where the residual stresses in austenitic, ferritic, and duplex stainless steels were examined. For welded I-sections, only membrane residual stresses are generally significant and through-thickness bending residual stresses can be typically ignored [29]. Based on the results of Lagerqvist and Olsson [35] and Bredenkamp et al. [36], Gardner and Cruise [29] proposed a residual stress model for welded stainless steel I-sections; this model is adopted in the present study.

Residual stresses were accounted for in the numerical models by creating partitions in the top and bottom flanges and the web of each section where the relevant stress blocks were applied, using the *INITIAL CONDITIONS command. Prior to the application of external loading, a preliminary load step to allow equilibration of the residual stresses was defined. Details of the implemented membrane residual stress model may be found in Gardner and Cruise [29]. 


\subsection{Validation of models and parametric studies}

The results from the numerical models, both with and without residual stresses, were initially compared to the laboratory test results generated herein on lean duplex stainless steel stub columns and beams to assess the accuracy and validity of the FE simulations. In addition to the general load-deformation response and failure modes, key values were compared, including ultimate loads $\mathrm{N}_{\mathrm{u}}$ and moments $\mathrm{M}_{\mathrm{u}}$.

The results obtained from models with residual stresses showed little variation from those without residual stresses. Typical examples of this are given in Fig. 19, showing the FE moment-deformation responses for cross-sections I-200 $\times 140 \times 6 \times 6-1$ and I$200 \times 140 \times 12 \times 8-1$ in 3 -point bending. For the configurations examined, the effect of residual stresses was consistently very small; thus residual stresses were excluded from the future models, which led to significantly improved numerical stability.

Table 9 shows a comparison between the key numerical results (without residual stresses) and the laboratory results, considering four imperfection amplitudes. Using the measured imperfection amplitudes, an average ratio of FE to test ultimate load of 0.97 with a coefficient of variation (COV) of 0.06 was achieved. In addition to ultimate load, the stiffness, failure mode and general load-deflection, moment-rotation, and moment-curvature curves obtained from the FE models were generally in good agreement with those obtained from the experiments. Typical numerical failure modes from the stub column tests, the 3-point bending tests and the 4-point bending tests are shown in Figs 20-22, respectively. A comparison between the experimental and numerical load-end shortening, normalised moment-rotation and normalised momentcurvature curves for some typical tested sections are depicted in Figs 23-25, respectively.

When imperfection amplitudes other than the measured ones were employed, the mean ratio of FE to test ultimate load varied between 0.97 for the Dawson and Walker models and the $t / 100$ imperfection and 1.00 for the $t / 1000$ imperfection. The COV remained similar in all cases. The largest deviation between the test ultimate load and the FE ultimate loads using the Dawson and Walker imperfection model is $7 \%$, which is the 
least of the three imperfection models considered. Given this, and considering its successful application in similar previous studies [37], the Dawson and Walker model was chosen to determine the imperfection amplitudes for the parametric studies.

Having validated the FE models, a series of parametric studies were initiated. The aim of the parametric studies was to expand the available results over a wider range of crosssection slendernesses in order to assess the general structural behaviour of lean duplex stainless steel welded I-sections and to investigate the applicability of codified slenderness limits. A total of 36 parametric results were generated. The basic geometry of the components considered in the parametric studies, including member length, section height and flange width were kept constant. The thickness of the flanges and the webs were varied to cover a range of cross-section slenderness $\mathrm{c} / \mathrm{t} \varepsilon$ of between 25 and 56 for the stub columns and between 5 and 115 for beams, where, in accordance with Eurocode 3: Part 1-4 [7], $\mathrm{c}$ is the flat element width, $\mathrm{t}$ is the element thickness and $\varepsilon=\left[\left(235 / \sigma_{0.2}\right)(\mathrm{E} / 210000)\right]^{0.5}$. Furthermore, for the 3-point and 4-point beams two cases

- the flange being the most critical element and the web being the most critical element - were considered. The basic modelling assumptions were as described previously. The material stress-strain curve adopted for the parametric studies was derived from the average of the experimental stress-strain curves of the four tested plate thicknesses.

\section{Analysis of results and design recommendations}

\subsection{Introduction}

The results from the laboratory tests and the numerical analyses on welded I-sections carried out in the present study, together with the results of previous laboratory tests on lean duplex stainless steel cold-formed hollow sections $[5,6]$, are used to assess the applicability of the current cross-section classification limits of Eurocode 3: Part 1.4 [7], the proposed limits of Gardner and Theofanous [38], and the continuous strength method (CSM) $[8,9]$ to lean duplex stainless steel. All comparisons have been carried out using the measured geometry and material properties. Finally, the structural 
performance of lean duplex stainless steel will be compared to that of the austenitic, ferritic and duplex grades.

\subsection{Slenderness limits}

The most significant difference in terms of structural response between stainless steel and carbon steel stems from their stress-strain relationships. Stainless steel exhibits a rounded stress-strain curve with no sharp yield point, high ductility, and significant strain hardening, whereas carbon steel exhibits a stress-strain relationship with a sharp yield point and some strain hardening. Eurocode 3: Part 1.4 [7] treats stainless steel similarly to carbon steel by considering the material model of stainless steel to be elastic-perfectly plastic. Following this assumption, the nominal yield stress of stainless steel is considered to be the $0.2 \%$ proof stress $\sigma_{0.2}$. Furthermore, similar to the carbon steel cross-section classification found in Eurocode 3: Part 1.1 [39], but with differences in the slenderness limits and effective width formulae, Eurocode 3: Part 1.4 [7] defines four cross-section classes (Class 1, 2, 3 and 4) based on the width-to-thickness ratios of the constituent elements. In compression, distinction is only made between Class 1-3 cross-sections that can attain their yield load $\left(A \sigma_{0.2}\right)$ and Class 4 cross-sections that, due to local buckling, cannot. In bending, cross-sections that are capable of attaining and maintaining their full plastic moment capacity $\mathrm{M}_{\mathrm{pl}}$ with sufficient deformation capacity for plastic design are considered to be of Class 1. Class 2 cross-sections are those that are capable of attaining their full plastic moment capacity. Cross-sections capable of attaining their elastic moment capacity $\mathrm{M}_{\mathrm{el}}$ before are classified as Class 3, and finally those where local buckling prevents $\mathrm{M}_{\mathrm{el}}$ from being reached are Class 4 . It is worth nothing that although EN 1993-1-4 [7] differentiates between Class 1 and Class 2 sections through the provision of separate slenderness limits, plastic design is disallowed in the code. A summary of the current codified slenderness limits for carbon steel [39] and stainless steel [7], together with those proposed by Gardner and Theofanous [38], are presented in Table 10.

\subsubsection{Compression}

The results obtained from the stub column tests and FE models are shown in Fig. 26, where the key response characteristic $\mathrm{N}_{\mathrm{u}} / A \sigma_{0.2}$ is plotted against the slenderness of the 
most slender constituent element in the cross-section (this being the internal web element in all cases), $\mathrm{c}_{\mathrm{w}} / \mathrm{t}_{\mathrm{w}} \varepsilon$, where $\mathrm{c}_{\mathrm{w}}$ is the depth of the web [7], $\mathrm{t}_{\mathrm{w}}$ is the thickness of the web, and $\varepsilon$ is defined in Eurocode 3: Part $1.4[7]$ as $\varepsilon=\left[\left(235 / \sigma_{0.2}\right)(\mathrm{E} / 210000)\right]^{0.5}$. It can be seen that on a normalised basis the welded I-sections and cold-formed hollow sections results exhibit a common trend. It can also be concluded that the current Class 3 slenderness limit of $30.7 \varepsilon$ as given in Eurocode 3: Part 1.4 [7] can be safely applied to lean duplex stainless steel but the proposed limit [38] of $37 \varepsilon$ will provide added economy.

\subsubsection{Bending}

The results obtained from the experimental and numerical studies for the cases of 3point and 4-point bending were collected and analysed. For the tested welded I-sections, the outstand flange element was found to be the most slender element in the crosssection, while in the numerical analysis, the two cases of flange-critical and webcritical were considered. For the previous bending tests on cold-formed lean duplex stainless steel hollow sections [6], the internal compression element was critical in all cases, allowing no direct comparison to the results on welded I-sections obtained herein. The relevant response characteristics $M_{u} / M_{e l}, M_{u} / M_{p l}$, and the rotation capacity $\mathrm{R}$ to investigate the Class 3, 2 and 1 slenderness limits, respectively, are plotted against the slenderness of the most slender constituent element in the cross-section, $\mathrm{c}_{\mathrm{w}} / \mathrm{t}_{\mathrm{w}} \varepsilon$ (when the web is critical) and $c_{f} / t_{f} \varepsilon$ (when the flange is critical), where $c_{f}$ is the width of the outstand flange [7], and $t_{f}$ is the thickness of the flange, in Figs 27-32. Note that rotation capacity $\mathrm{R}$ is generally defined as the normalised rotation at which the moment capacity drops below $\mathrm{M}_{\mathrm{pl}}$ following plastic deformation. However, due to excessive deformation, this point was not reached in a number of the tests (see Figs 17 and 18) and hence the presented values are conservatively based on the maximum rotations that were achieved. A rotations capacity requirement of $\mathrm{R}=3$ has been assumed for a Class 1 cross-section, as used in the development of Eurocode 3 for carbon steel [39].

Firstly, from Figs 27-32 it may be observed that beams tested in the 3-point configuration have greater resistance than those in the 4-point configuration. This is a commonly observed phenomenon and relates to the restricted local buckling wavelength that arises in the 3-point configuration due to the moment gradient. 
Similarly to the findings of Section 4.2.1, both Class 3 limits of $11 \varepsilon$ and $74.8 \varepsilon$ in EN 1993-1-4 [7] for welded outstand flanges in compression and internal webs in bending respectively, were found to be safe, but conservative - see Figs 27 and 28, while, the proposed limits [38] of $14 \varepsilon$ and $90 \varepsilon$ allow for more cross-sections to be considered as Class 3, thus providing more economic designs. The same conclusion applies to Class 2 cross-sections, where the limits of EN 1993-1-4 [7] are found to be safely applicable to both welded outstand elements in compression and internal web elements in bending, as shown in Figs 29 and 30. However, the proposed limits [38] offer greater efficiency and allow for more cross-sections to be considered Class 2 rather than Class 3.

Finally, Class 1 cross-section requirements are considered in Figs 31 and 32 where the rotation capacity from both the experiments and FE data were plotted. The EN 1993-14 [7] limits for Class 1 cross-sections may be seen to be safely applicable to lean duplex stainless steel, while the more relaxed Class 1 limits proposed in [38] allow for more sections to be classified as Class 1 on the basis of a rotation capacity of $\mathrm{R}=3$, though as previously mentioned, plastic design is not currently allowed for stainless steel sections.

\subsection{Continuous strength method}

From the above comparisons, it was shown that proposed slenderness limits [38] offer a better estimation of the cross-section behaviour when compared to the current provisions of EN 1993-1-4 [7] but the accuracy of prediction of cross-section capacity is still limited by the analogy with carbon steel and neglection of strain hardening. The continuous strength method (CSM) is a recently developed deformation-based design method [8,9] that replaces traditional cross-section classification with a continuous non-dimensional measure of the deformation capacity of a cross-section, and employs a strain hardening material model to assess accurately the capacity of stainless steel cross-sections. A detailed description of CSM can be found in $[8,9]$ while the key design expressions adopted in this paper are briefly described herein. 
The continuous strength method defines the section slenderness on the basis of the full cross-section [40] or, conservatively on the basis of the most slender constituent element (Eq. 6), thus:

$$
\bar{\lambda}_{\mathrm{p}}=\sqrt{\frac{\sigma_{0.2}}{\sigma_{\mathrm{cr}}}}
$$

where $\sigma_{0.2}$ is the material $0.2 \%$ proof stress and $\sigma_{\mathrm{cr}}$ is the elastic buckling stress.

The CSM limiting stress $\sigma_{\mathrm{csm}}$ is determined directly from the strain hardening material model defined in $[8,9]$ and is given by Eq. 7 :

$$
\sigma_{\mathrm{csm}}=\sigma_{0.2}+\mathrm{E}_{\mathrm{sh}}\left(\varepsilon_{\mathrm{csm}}-\varepsilon_{\mathrm{y}}\right) \text { for } \varepsilon_{\mathrm{csm}} \geq \varepsilon_{\mathrm{y}}
$$

where the normalised deformation capacity of the cross-section $\varepsilon_{\mathrm{csm}} / \varepsilon_{\mathrm{y}}$ is obtained through Eq. 8:

$$
\frac{\varepsilon_{\mathrm{csm}}}{\varepsilon_{\mathrm{y}}}=\frac{0.4}{\bar{\lambda}_{\mathrm{p}}^{3.2}} \text { but } \frac{\varepsilon_{\mathrm{csm}}}{\varepsilon_{\mathrm{y}}} \leq \operatorname{minimum}\left(15, \frac{0.10 \varepsilon_{\mathrm{u}}}{\varepsilon_{\mathrm{y}}}\right) \text { for } \bar{\lambda}_{\mathrm{p}} \leq 0.748
$$

in which $\varepsilon_{\mathrm{y}}=\sigma_{0.2} / \mathrm{E}$ is the yield strain of the material, $\mathrm{E}$ is the Young's modulus, $\varepsilon_{\mathrm{csm}}$ is the CSM limiting strain of the section, $\varepsilon_{\mathrm{u}}$ is the strain at the ultimate tensile stress, taken as $\varepsilon_{\mathrm{u}}=1-\sigma_{0.2} / \sigma_{\mathrm{u}}$ and $\mathrm{E}_{\mathrm{sh}}$ is the strain hardening slope defined as follows in Eq. 9:

$$
\mathrm{E}_{\mathrm{sh}}=\frac{\left(\sigma_{\mathrm{u}}-\sigma_{0.2}\right)}{\left(0.16 \varepsilon_{\mathrm{u}}\right)-\left(\varepsilon_{\mathrm{y}}+0.002\right)}
$$

where $\sigma_{\mathrm{u}}$ is the ultimate tensile stress.

The predicted capacities of the tested sections in compression and bending, according to the CSM, EN 1993-1-4 [7], and the proposed slenderness limits [38] are presented in Table 11. The comparisons show that the CSM gives improved predictions for the stub column tests and the bending tests over both the EN 1993-1-4 [7] and the proposed 
limits [38]. It should be noted that the CSM is not applied to elements whose slenderness exceeds the specified limit of application of $\bar{\lambda}_{p} \leq 0.748$.

\subsection{Comparison with other stainless steel grades}

Lean duplex is a relatively new grade of stainless steel and there is limited knowledge about its structural behaviour. To assess the performance of lean duplex stainless steel relative to other stainless steel families - austenitic, ferritic, and duplex - a number of comparisons are presented in this section. The results obtained from the stub column tests performed on lean duplex stainless steel welded I-sections and cold-formed hollow sections [5] were compared to existing test results from other grades [41-43], in Fig. 33. Upon examination of the results, two main conclusions can be drawn. First, for similar values of slenderness the results from the lean duplex sections exhibit similar (normalised) performance to equivalent sections of other stainless steel grades. Second, the results show that the Eurocode 3: Part 1.4 [7] Class 3 limits are conservative and that the proposed limits [38] allow for more sections to be designed as Class 3 crosssections.

The results obtained from the 4-point bending tests performed on welded I-sections were also compared to test results from other grades [43, 44], in Figs 34 and 35. The comparisons show similar normalised performance between the grades, and demonstrate that both the codified [7] and proposed slenderness limits [38] are safely applicable.

\section{Conclusions}

An experimental and numerical programme investigating the structural behaviour of lean duplex stainless steel welded I-sections has been performed at Imperial College London. A total of 24 material tests, 4 stub column tests and 8 bending tests were conducted. The specimen geometries, including measurements of initial imperfections, and test results, including full load-deformation histories, have been fully reported. Numerical models were validated against the experimental results, after which parametric studies were carried out to generate further structural performance data on 
lean duplex stainless steel. The obtained results from both the experiments and the numerical analysis were used to evaluate the applicability of existing design approaches to lean duplex stainless steel. It was found that the current Eurocode 3: Part 1.4 section classification limits may be safely adopted but greater economy can be achieved by employing the proposed limits of Gardner and Theofanous. Further improvements in efficiency could be achieved using the continuous strength method. The test results on lean duplex stainless steel were also compared to results obtained from tests performed on austenitic, ferritic and duplex grades. The comparisons show that, on a normalised basis, the behaviour is similar to other stainless steel grades, and hence, lean duplex stainless steel can be added to future revisions of EN 1993-1-4. Overall, the high strength, good corrosion resistance and moderate cost of lean duplex stainless steel make this material an attractive choice for structural applications.

\section{References}

[1] EN 10088-4. (2009). Stainless steels - Part 4: Technical delivery conditions for sheet/plate and strip of corrosion resisting steels for general purposes. CEN.

[2] Gardner, L., Insausti, A., Ng, K. T. and Ashraf, M. (2010). Elevated temperature material properties of stainless steel alloys. Engineering Structures. 66(5), 634-647.

[3] Nilsson, J. O., Chai, G. and Kivisäkk, U. (2008). Recent development of stainless steels, Proceedings of the Sixth European Stainless steel Conference, 10-13 June 2008. 585-590. Helsinki, Finland.

[4] Sieurin, H., Sandström, R. and Westin, E.M. (2007). Fracture toughness of the lean duplex stainless steel LDX 2101. Metallurgical and Materials Transactions A, 37(10), 2975-2981.

[5] Theofanous, M. and Gardner, L. (2009). Testing and numerical modelling of lean duplex stainless steel hollow section columns. Engineering Structures. 31(12), 30473058. 
[6] Theofanous, M. and Gardner, L. (2010). Experimental and numerical studies of lean duplex stainless steel beams. Journal of Constructional Steel Research. 66(6), 816-825. [7] EN 1993-1-4. (2006). Eurocode 3: Design of steel structures - Part 1.4: General rules - Supplementary rules for stainless steel. CEN.

[8] Gardner, L. (2008). The continuous strength method. Proceedings of the Institution of Civil Engineers-Structures and Buildings. 161(3), 127-133.

[9] Gardner, L., Wang, F. and Liew, A. (2011). Influence of strain hardening on the behaviour and design of steel structures. International Journal of Structural Stability and Dynamics. 11(5), 855-875.

[10] EN 10002-1. (2001). Metallic materials-Tensile testing, Part 1: Method of test at ambient temperature. CEN.

[11] Mirambell, E. and Real, E. (2000). On the calculation of deflections in structural stainless steel beams: an experimental and numerical investigation. Journal of Constructional Steel Research. 54(1), 109-133.

[12] Rasmussen, K.J.R. (2003). Full-range stress-strain curves for stainless steel alloys. Journal of Constructional Steel Research. 59(1), 47-61.

[13] Gardner, L. and Ashraf, M. (2006). Structural design for non-linear metallic materials. Engineering Structures. 28(6), 926-934.

[14] Hutchinson, W.B., Ushioda, K. and Runnsjo, G. (1985). Anisotropy of tensile behaviour in a duplex stainless-steel sheet. Materials Science and Technology. 1(9), 728-731.

[15] Saliba, N. and Gardner, L. (2012). Experimental study of the shear response of lean duplex stainless steel plate girders. Engineering Structures. (in press). 
[16] Schafer, B.W. and Peköz, T. (1998). Computational modelling of cold-formed steel: characterizing geometric imperfections and residual stresses. Journal of Constructional Steel Research 47(3), 193-210.

[17] Ziemian, R.D., editor. (2010). Guide to Stability Design Criteria for Metal Structures. 6th Edition, John Wiley \& Sons, Inc., New York.

[18] University of Sydney (1990). Compression tests of stainless steel tubular columns. Investigation Report S770. Centre for Advanced Structural Engineering, University of Sydney.

[19] Hibbitt, Karlsson \& Sorensen, Inc. (2010). ABAQUS. ABAQUS/Standard user's manual volumes I-III and ABAQUS CAE manual. Version 6.10. (Pawtucket, USA).

[20] Ellobody, E. and Young, B. (2005). Structural performance of cold-formed high strength stainless steel columns. Journal of Constructional Steel Research. 61(12), 1631-1649.

[21] Lecce, M. and Rasmussen, K. J. R. (2006). Distortional buckling of cold-formed stainless steel sections: Finite-element modelling and design. Journal of Structural Engineering, ASCE. 132(4), 505-514.

[22] Ramberg, W. and Osgood, W. R. (1943). Description of stress-strain curves by three parameters. Technical Note No 902, National Advisory Committee for Aeronautics Washington, D.C.

[23] Hill, H.N. (1944). Determination of stress-strain relations from offset yield strength values. Technical Note No 927, National Advisory Committee for Aeronautics. Washington, D.C.

[24] Abdella, K. (2007). An explicit stress formulation for stainless steel applicable in tension and compression. Journal of Constructional Steel Research. 63(3), 326-331. 
[25] Quach, W. M., Teng, J. G., and Chung, K. F. (2008). Three-stage full-range stressstrain model for stainless steels. Journal of Structural Engineering, ASCE. 134(9), 1518-27.

[26] Dawson, R.G. and Walker, A.C. (1972). Post-buckling of geometrically imperfect plates. Journal of the Structural Division, ASCE. 98(1), 75-94.

[27] Gardner, L. and Nethercot, D.A. (2004). Numerical modeling of stainless steel structural components-A consistent approach. Journal of Structural Engineering, ASCE. 130(10), 1586-1601.

[28] Gardner, L. and Ng, K.T. (2006). Temperature development in structural stainless steel sections exposed to fire. Fire Safety Journal. 41(3), 185-203.

[29] Gardner, L. and Cruise, R.B. (2009). Modeling of Residual Stresses in Structural Stainless Steel Sections. Journal of Structural Engineering, ASCE. 135(1), 42-53.

[30] Clarin, M. (2003). Measurement of longitudinal residual stresses in a cold formed rectangular hollow section. Structural Design of Cold Worked Austenitic Stainless Steel, Internal Rep. No. 2003-08-30, Lulea Univ. of Technology, Lulea, Sweden.

[31] Quach, W. M., Teng, J. G., and Chung, K. F. (2004). Residual stresses in steel sheets due to coiling and uncoiling: A closed form analytical solution. Engineering Structures. 26(9), 1249-1259.

[32] Young, B. and Lui, W.M. (2005). Behavior of cold-formed high strength stainless steel sections. Journal of Structural Engineering, ASCE. 131(11), 1738-1745.

[33] Jandera, M., Gardner, L. and Machacek, J. (2008). Residual stresses in cold-rolled stainless steel hollow sections. Journal of Constructional Steel Research. 64(11), 12551263.

[34] Schafer, B.W., Li, Z. and Moen, C.D. (2010). Computational modeling of cold formed steel. Thin-walled structures. 48(10-11), 752-762. 
[35] Lagerqvist, O., and Olsson, A. (2001). Residual stresses in welded I-girders made of stainless steel and structural steel. Proc., 9th Nordic Steel Construction Conference. 737-744. Helsinki, Finland.

[36] Bredenkamp, P. J., Van den Berg, G. J., and Van der Merwe, P. (1992). Residual stresses and the strength of stainless steel I-section columns. Proc., Structural Stability Research Council, Annual Technical Session, Pittsburgh, 69-86.

[37] Ashraf, M., Gardner, L. and Nethercot, D.A. (2006). Finite element modelling of structural stainless steel cross-sections. Thin-walled structures. 44(10) 1048-1062.

[38] Gardner, L. and Theofanous, M. (2008). Discrete and continuous treatment of local buckling in stainless steel elements. Journal of Constructional Steel Research. 64(11), 1207-1216.

[39] EN 1993-1-1. (2005). Eurocode 3: Design of steel structures - Part 1.1: General rules - General rules and rules for buildings. CEN.

[40] Schafer, B.W. (2008). Review: The Direct Strength Method of cold-formed steel member design. Journal of Constructional Steel Research. 64(7-8), 766-778.

[41] Kuwamura, H. (2003). Local buckling of thin-walled stainless steel members. Steel Structures. 3(3), 191-201.

[42] ECSC. (2000). Work Package 6 WP6. ECSC project - Development of the use of stainless steel in construction. Document RT810, Contract No. 7210 SA/ 842, The Steel Construction Institute, UK.

[43] ECSC. (2000). Work Package 2 WP2. ECSC project - Development of the use of stainless steel in construction. Document RT810, Contract No. 7210 SA/ 842, The Steel Construction Institute, UK. 
[44] Yamada, and Kato. (1988). Strength and deformation of H-shaped Stainless steel Beams. Japanese Institution of Architecture. Journal of the Kanto branch. 


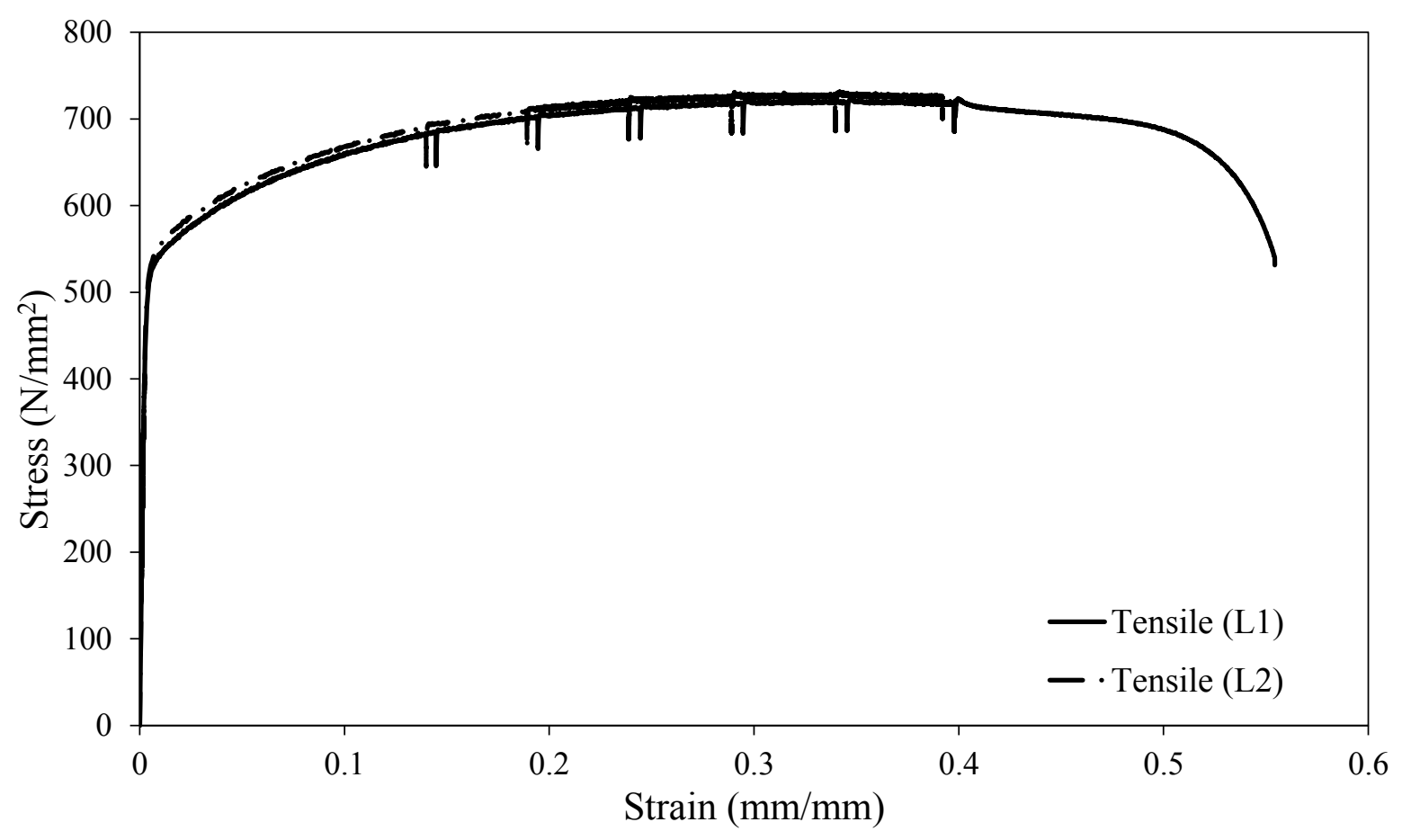

Fig. 1: Full tensile stress-strain curve for $6 \mathrm{~mm}$ material ( $\mathrm{L}=$ Longitudinal).

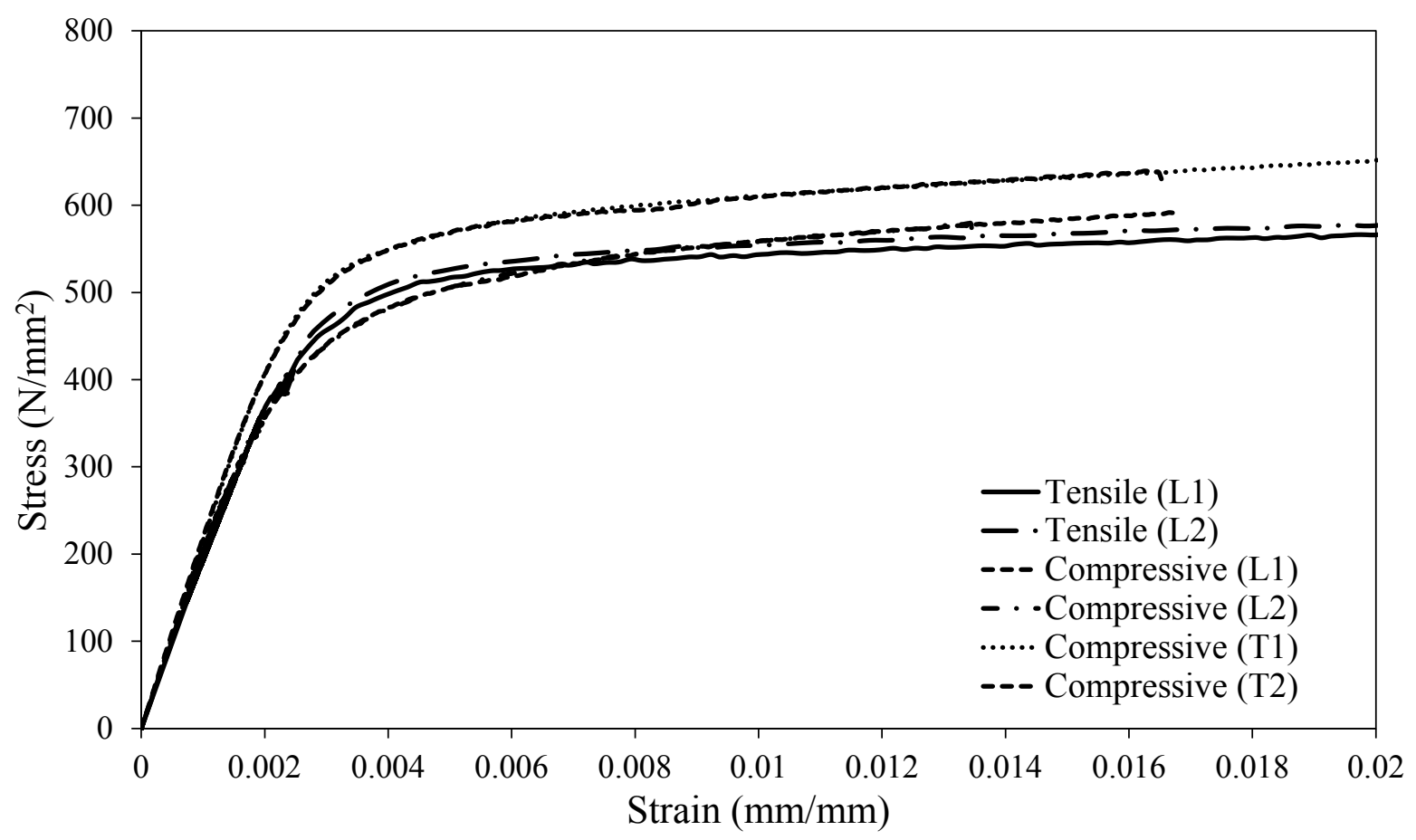

Fig. 2: Initial part of tensile and compressive stress-strain curves for $6 \mathrm{~mm}$ material $(\mathrm{L}=$ Longitudinal, T: Transverse). 


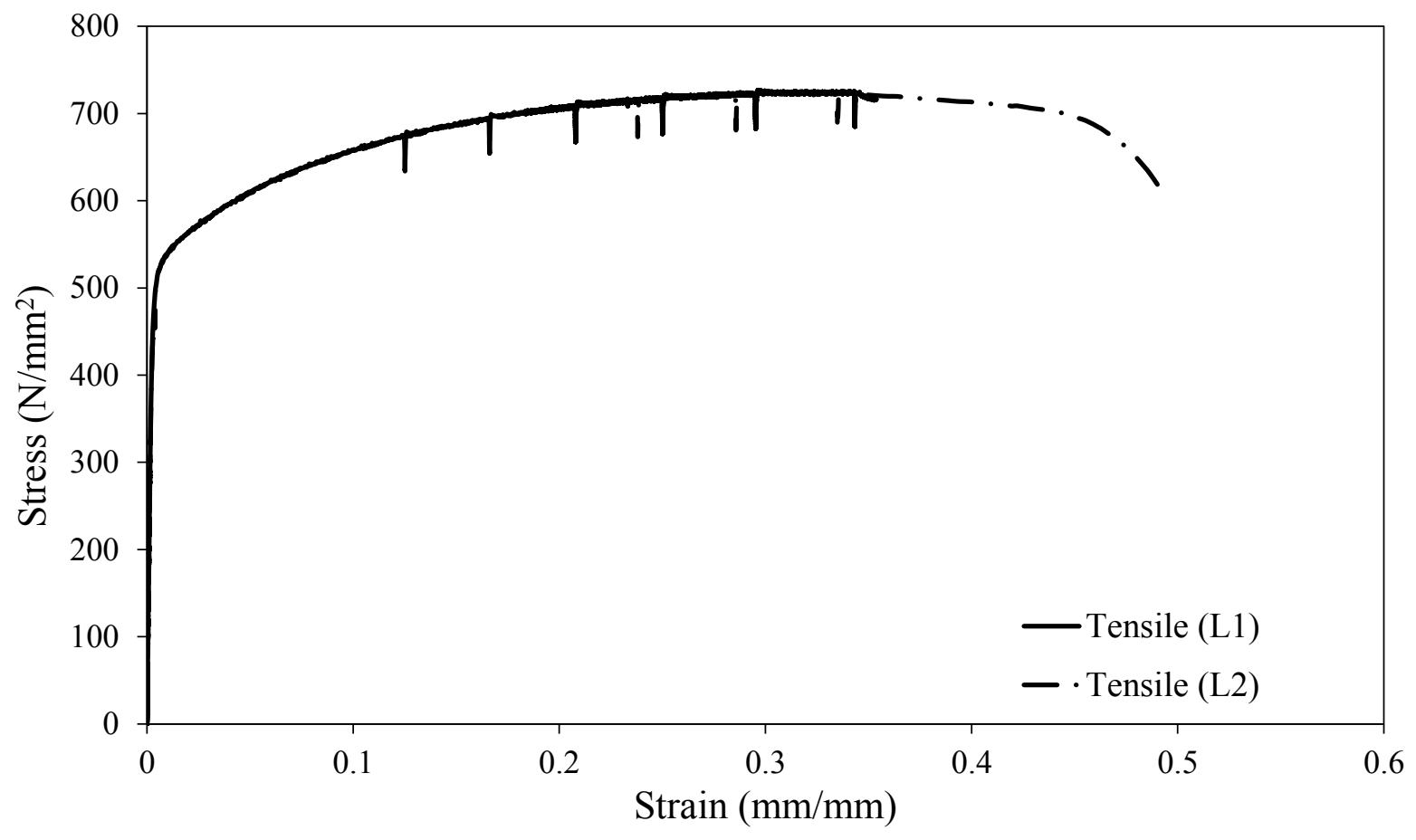

Fig. 3: Full tensile stress-strain curve for $8 \mathrm{~mm}$ material ( $\mathrm{L}=$ Longitudinal).

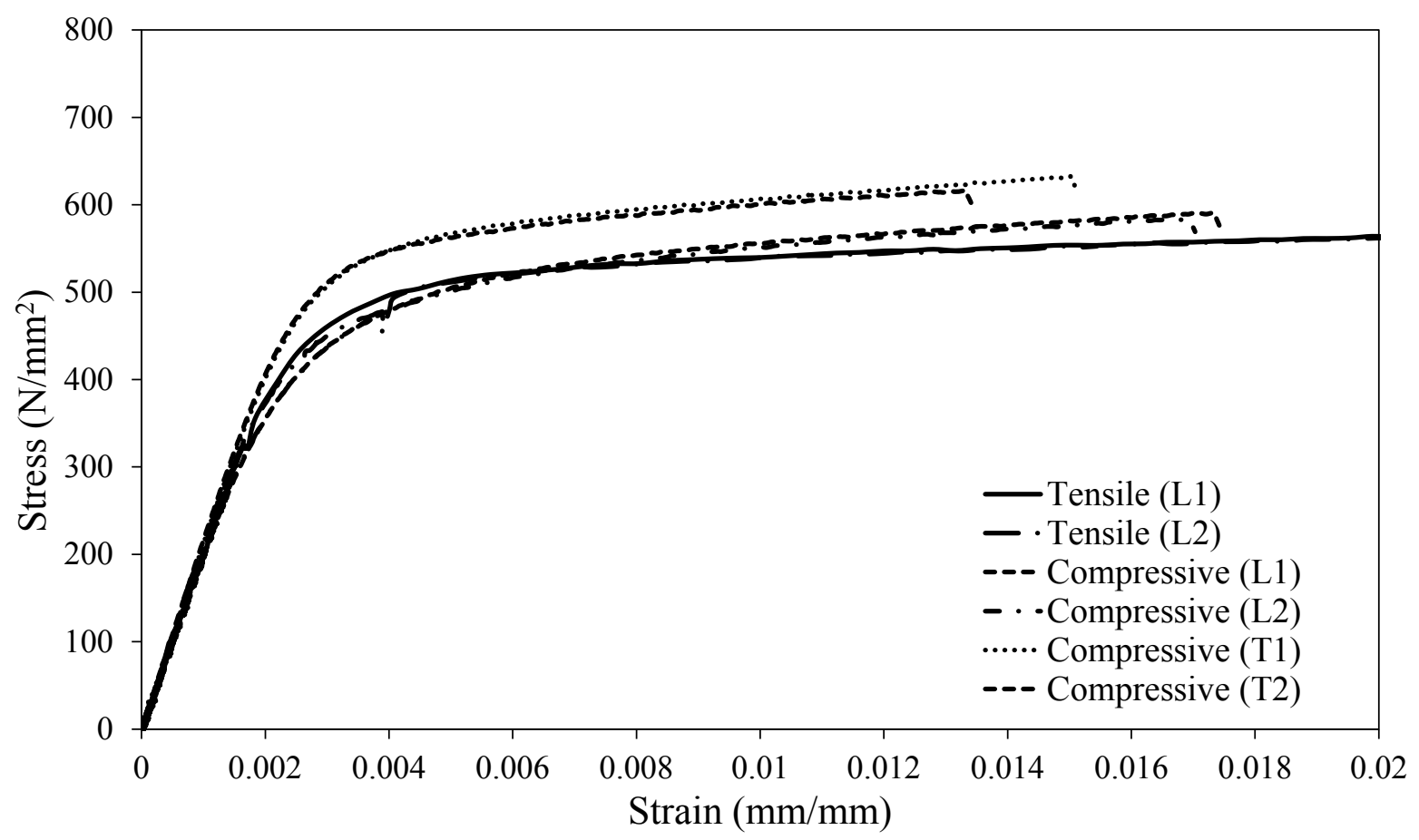

Fig. 4: Initial part of tensile and compressive stress-strain curves for $8 \mathrm{~mm}$ material $(\mathrm{L}=$ Longitudinal, $\mathrm{T}=$ Transverse). 


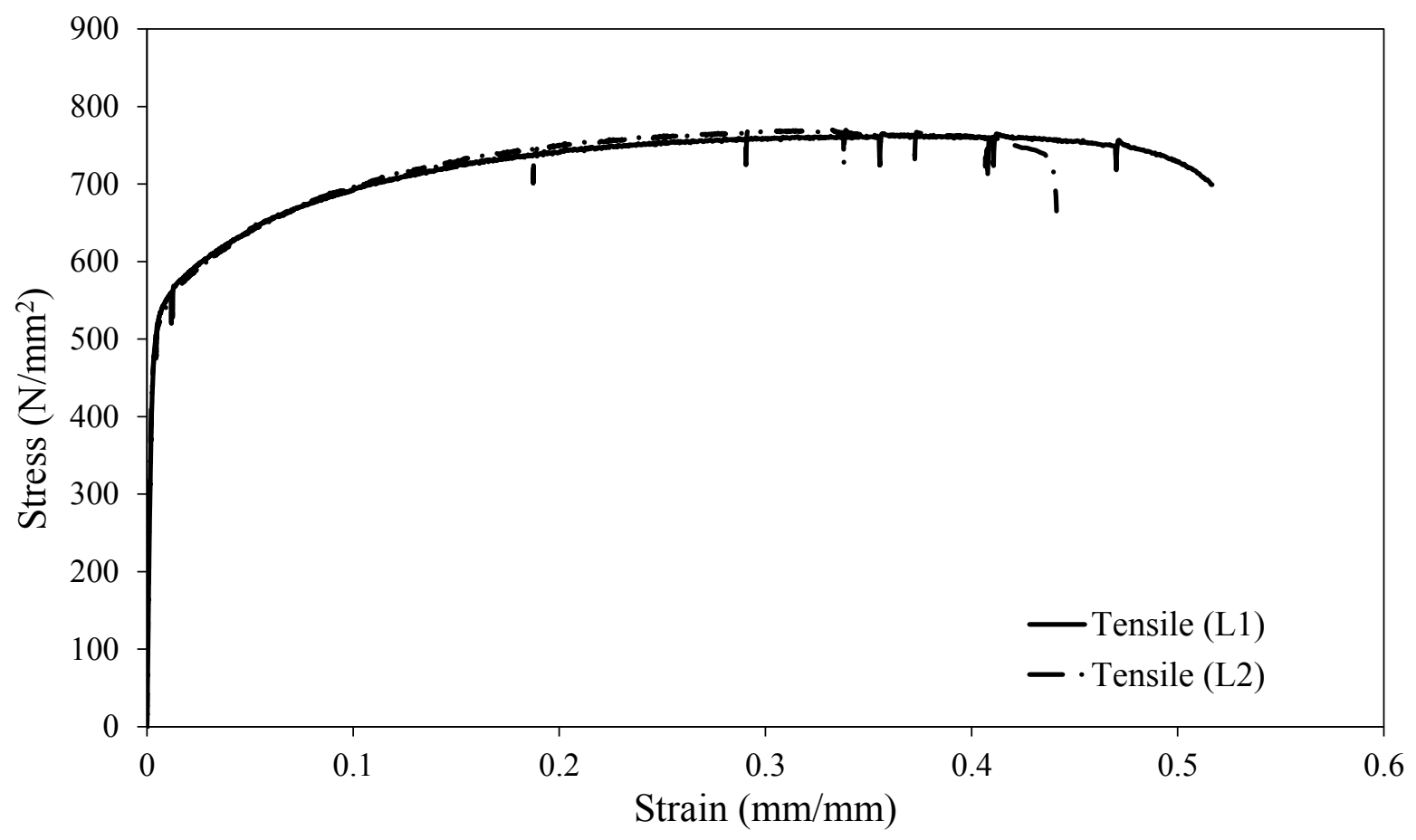

Fig. 5: Full tensile stress-strain curve for $10 \mathrm{~mm}$ material ( $\mathrm{L}=$ Longitudinal).

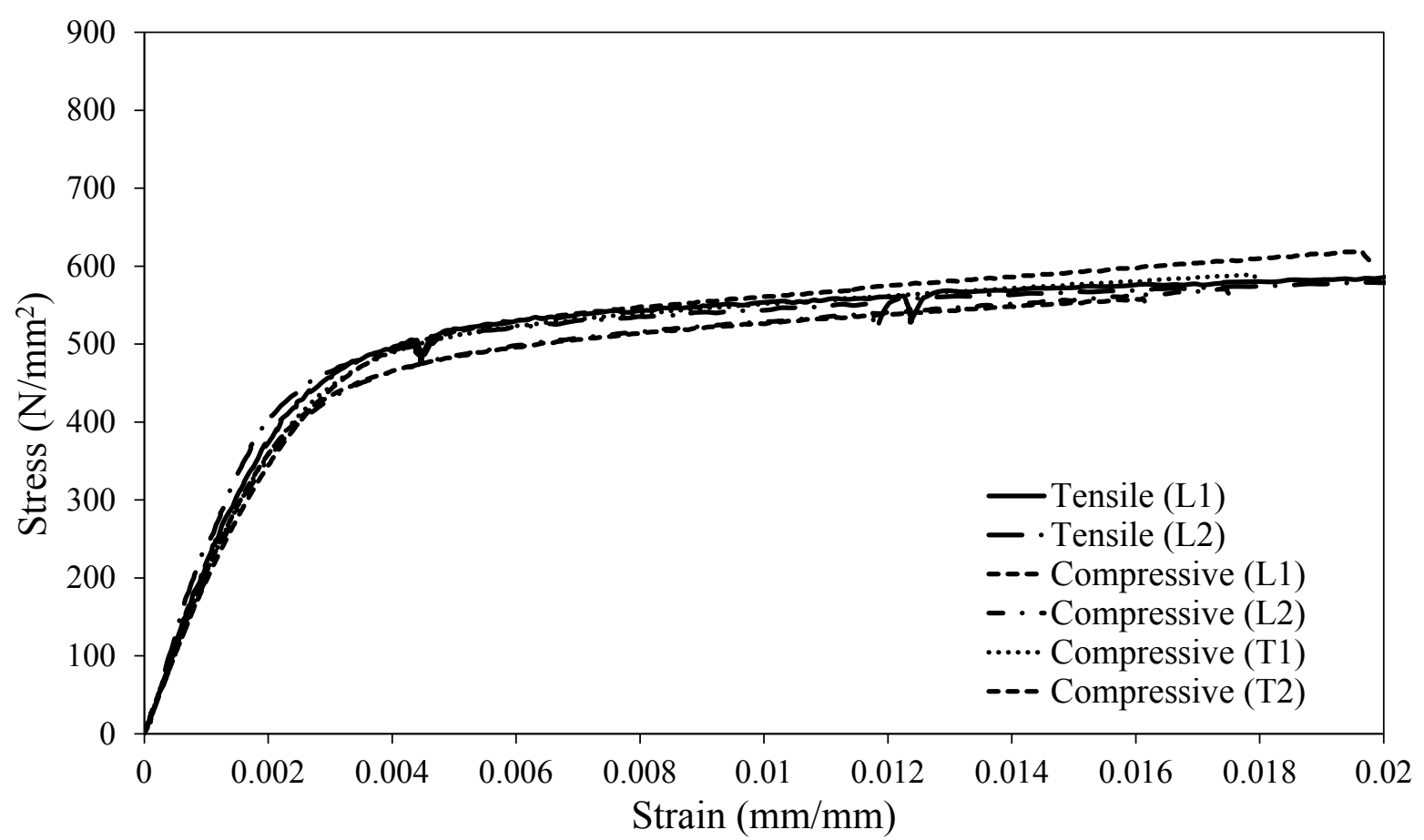

Fig. 6: Initial part of tensile and compressive stress-strain curves for $10 \mathrm{~mm}$ material $(\mathrm{L}=$ Longitudinal, $\mathrm{T}=$ Transverse). 


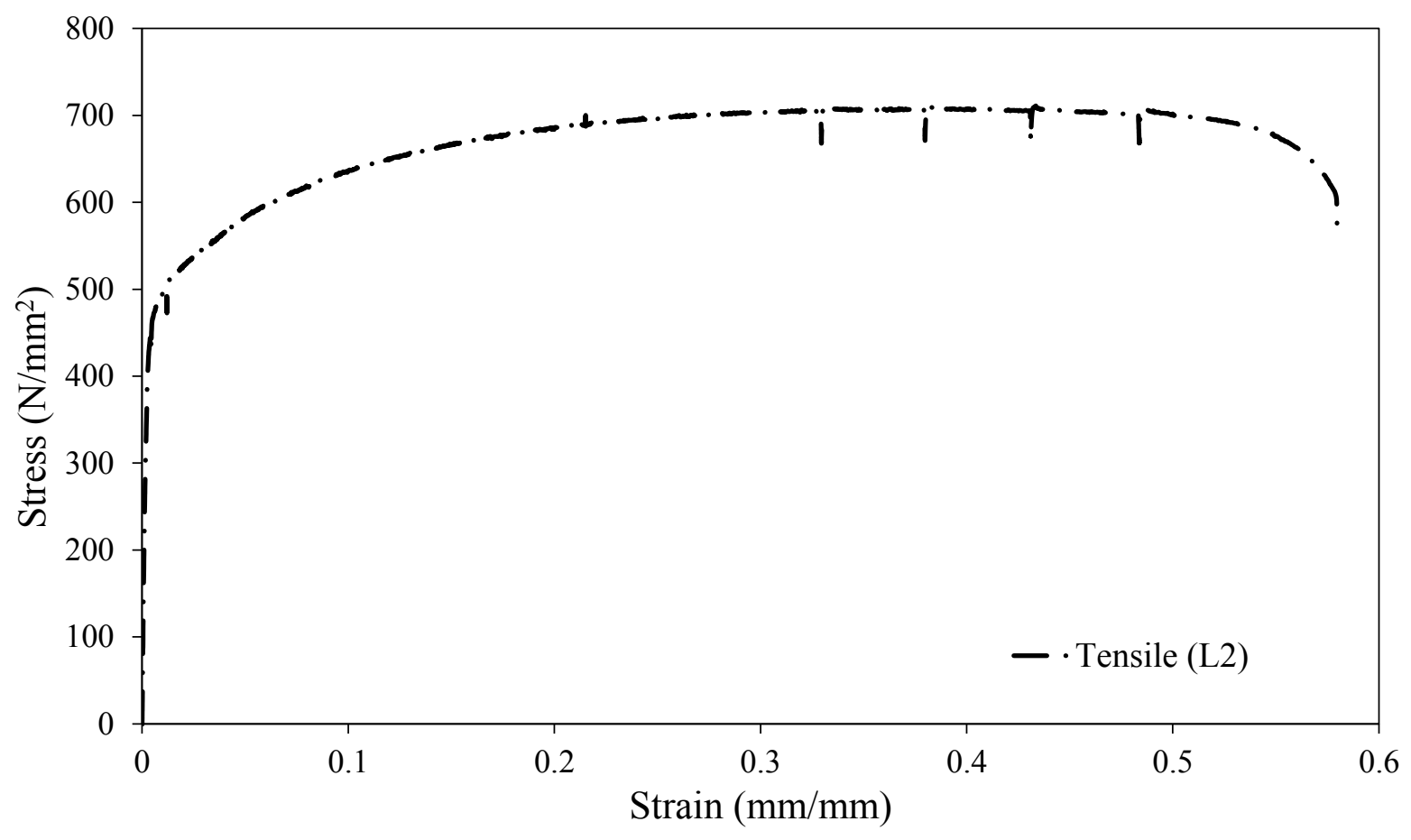

Fig. 7: Full tensile stress-strain curve for $12 \mathrm{~mm}$ material ( $\mathrm{L}=$ Longitudinal).

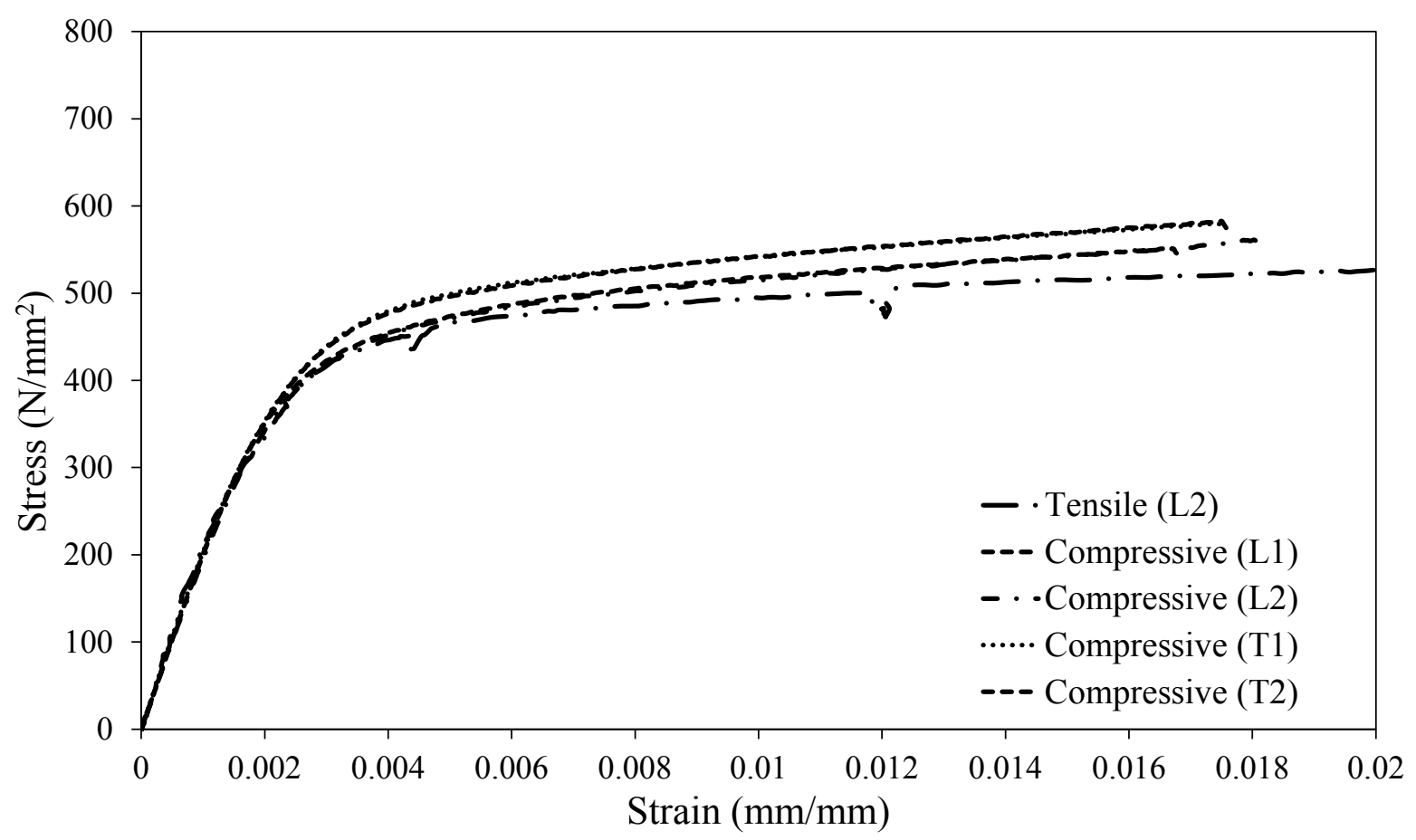

Fig. 8: Initial part of tensile and compressive stress-strain curves for $12 \mathrm{~mm}$ material $(\mathrm{L}=$ Longitudinal, $\mathrm{T}=$ Transverse). 


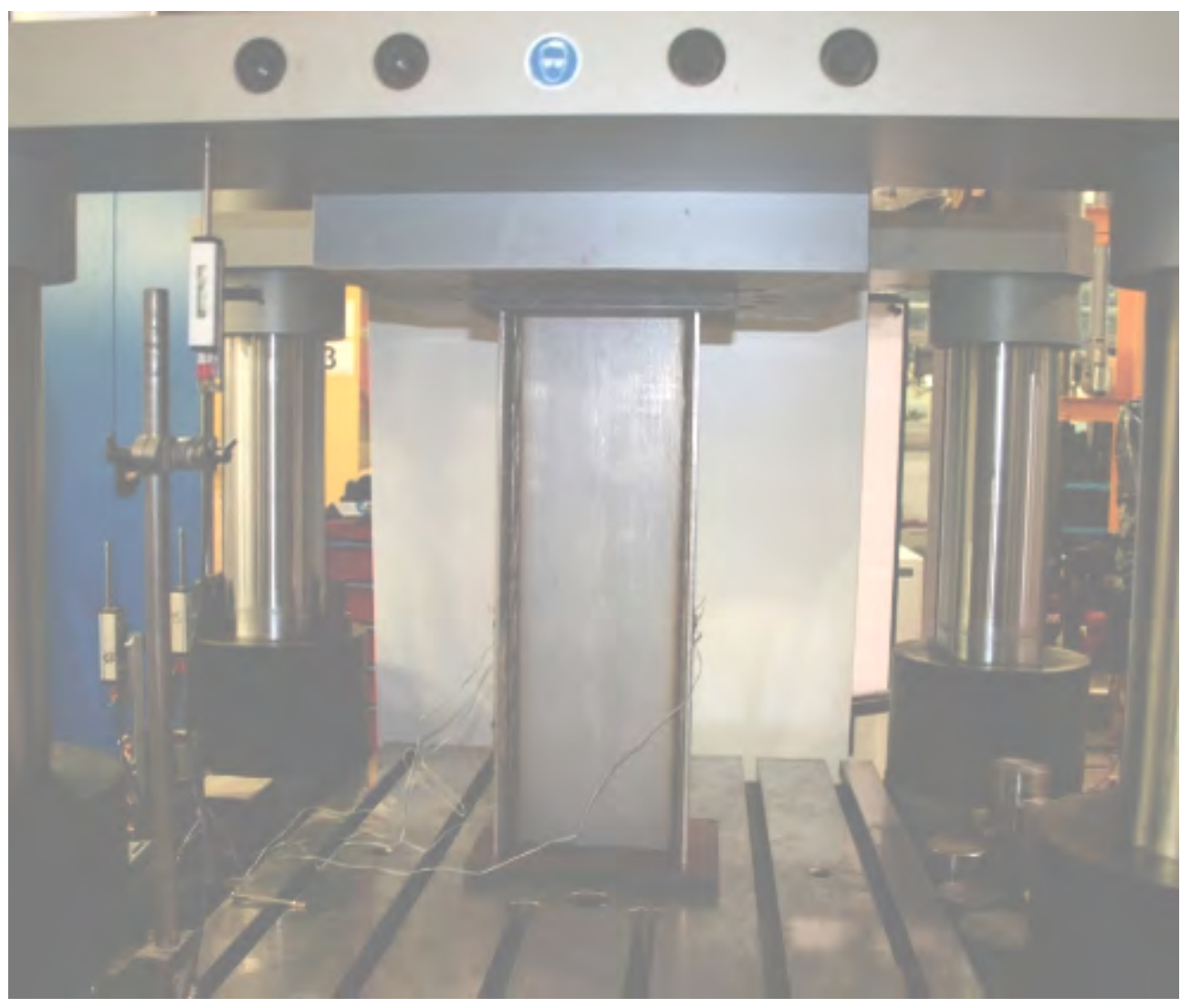

Fig. 9: Stub column test setup.

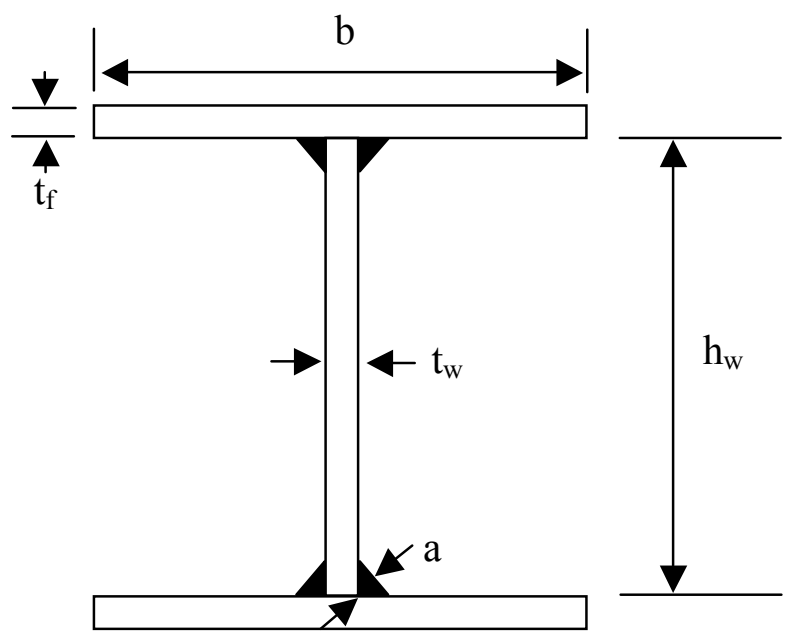

Fig. 10: Cross-section notation. 


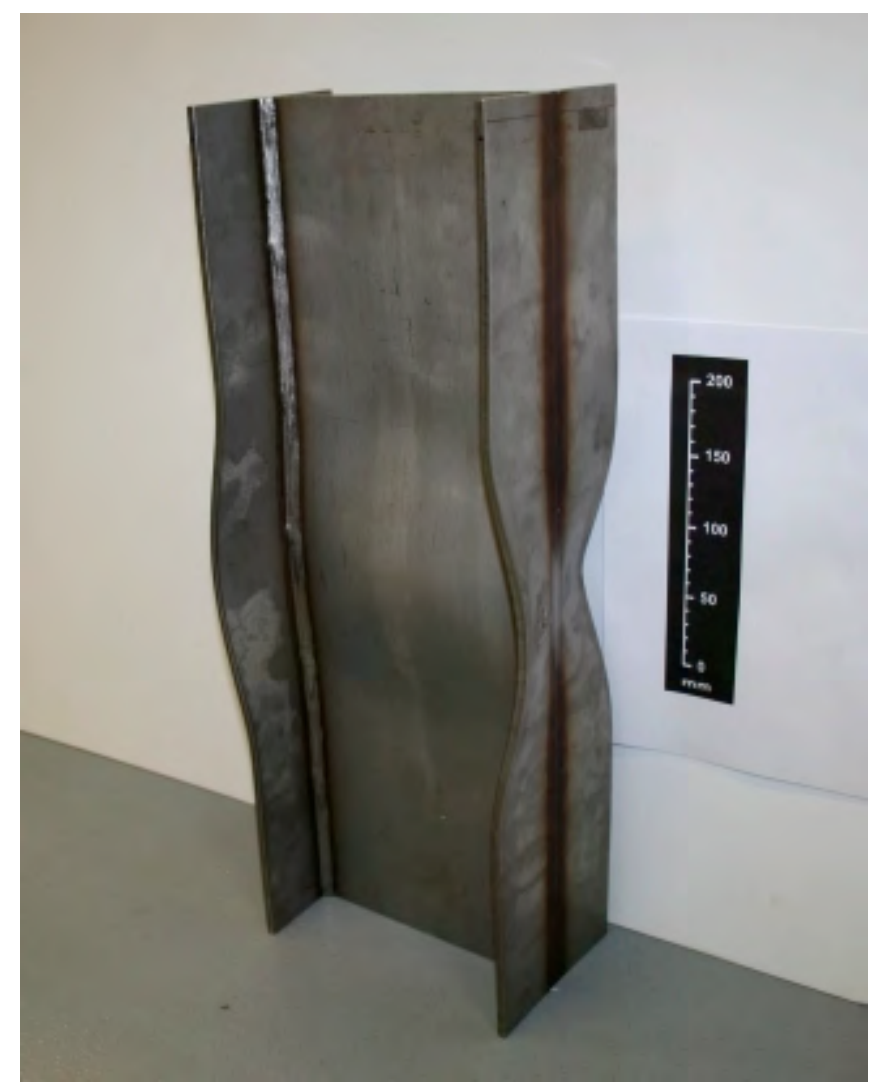

Fig. 11: Typical stub column failure mode.

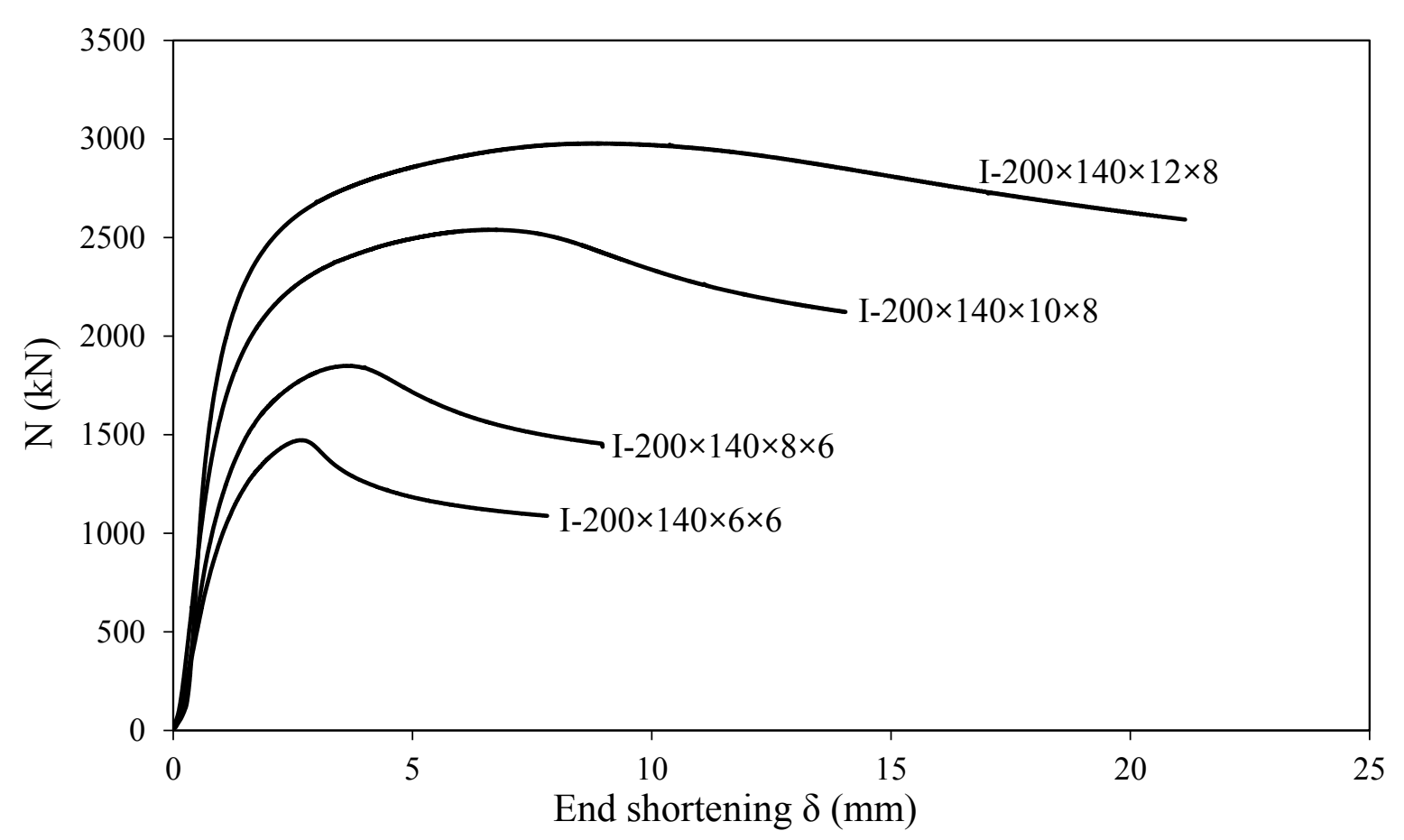

Fig. 12: Stub column load-end shortening curves. 


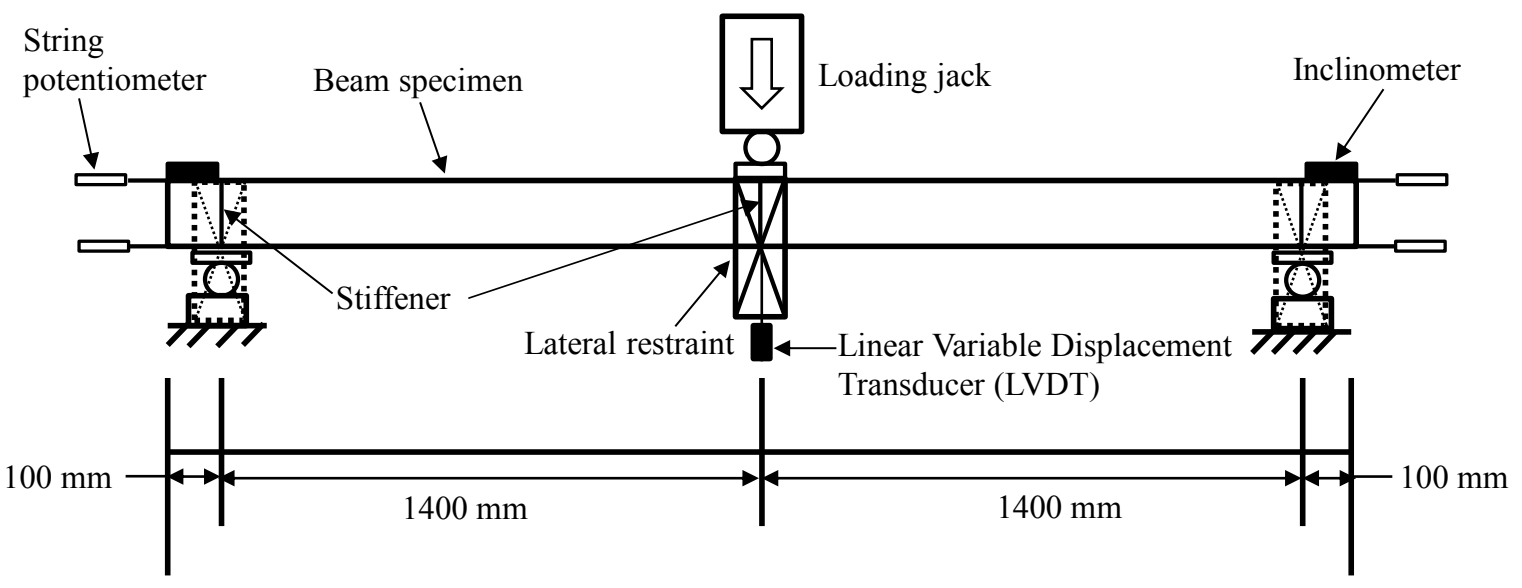

Fig. 13: Schematic 3-point bending test arrangement.

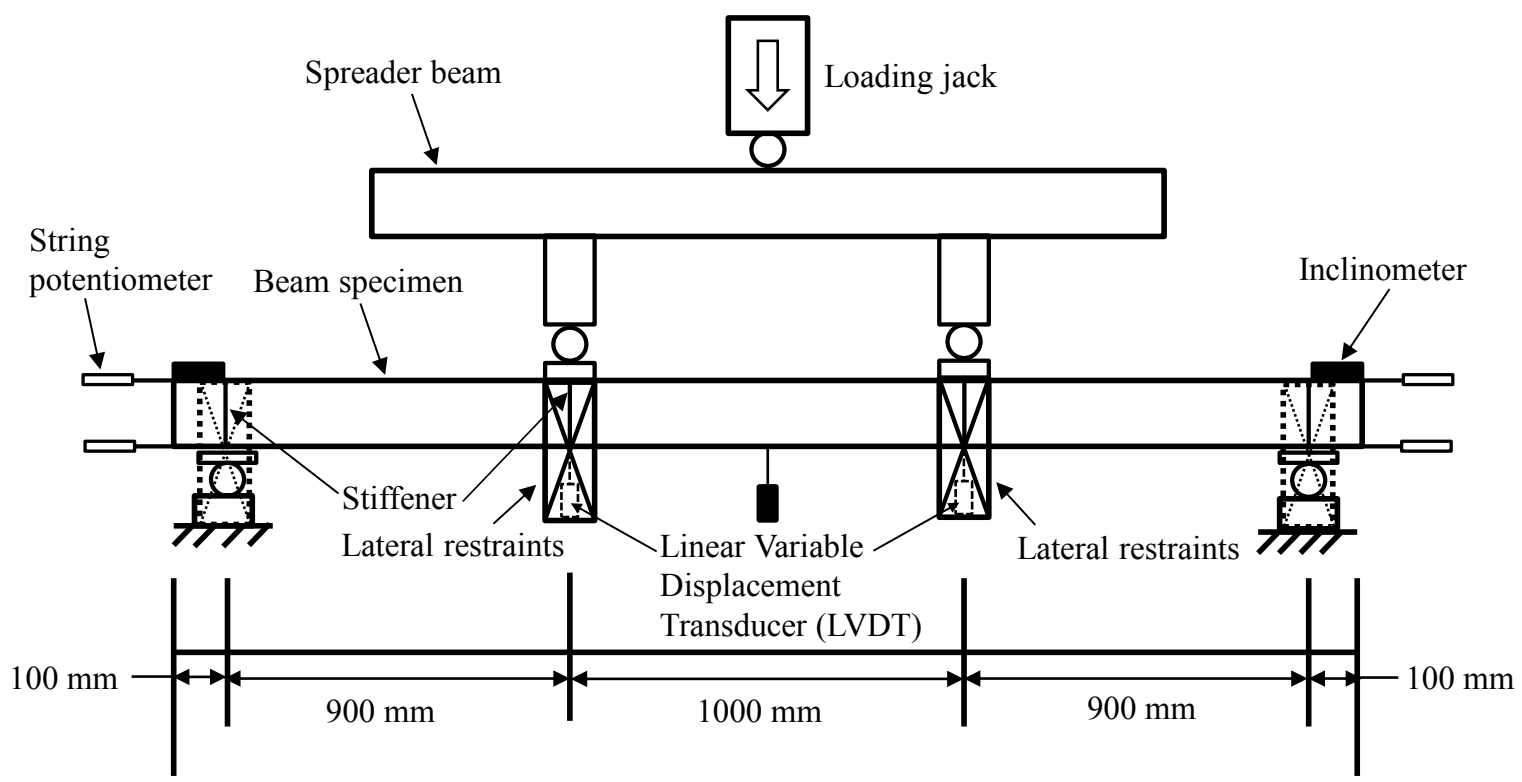

Fig. 14: Schematic 4-point bending test arrangement. 


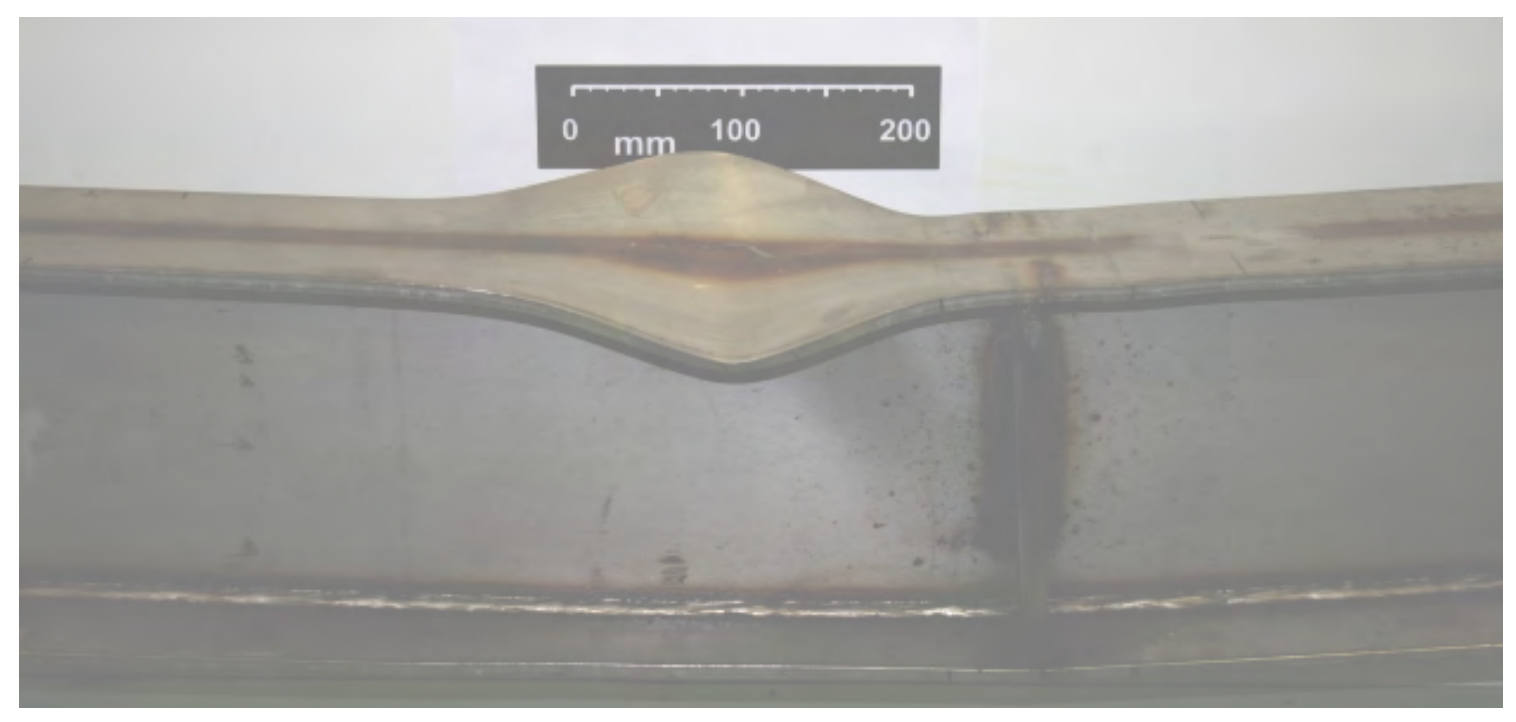

Fig. 15: Typical failure mode from 3-point bending tests.

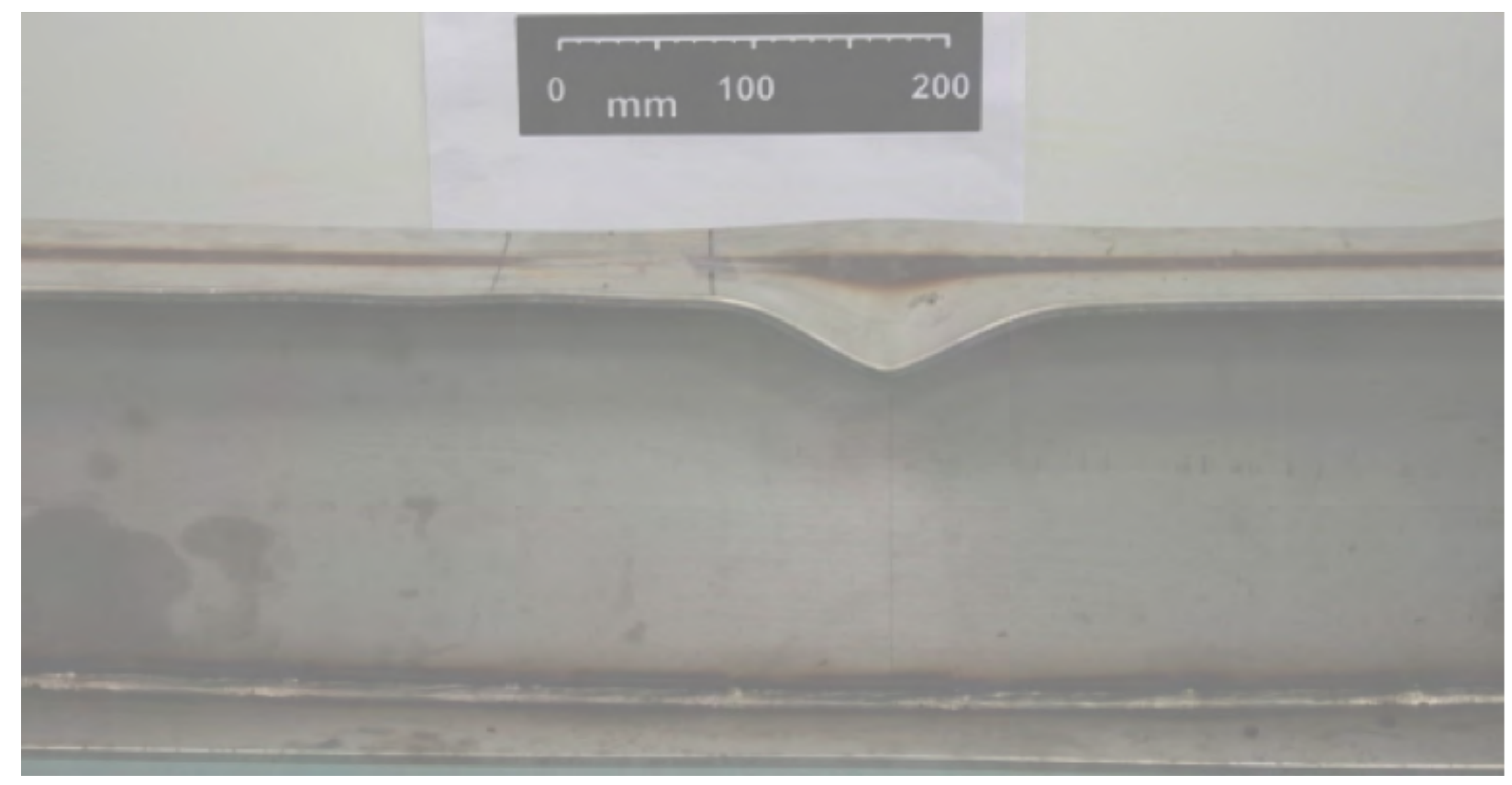

Fig. 16: Typical failure mode from 4-point bending tests. 


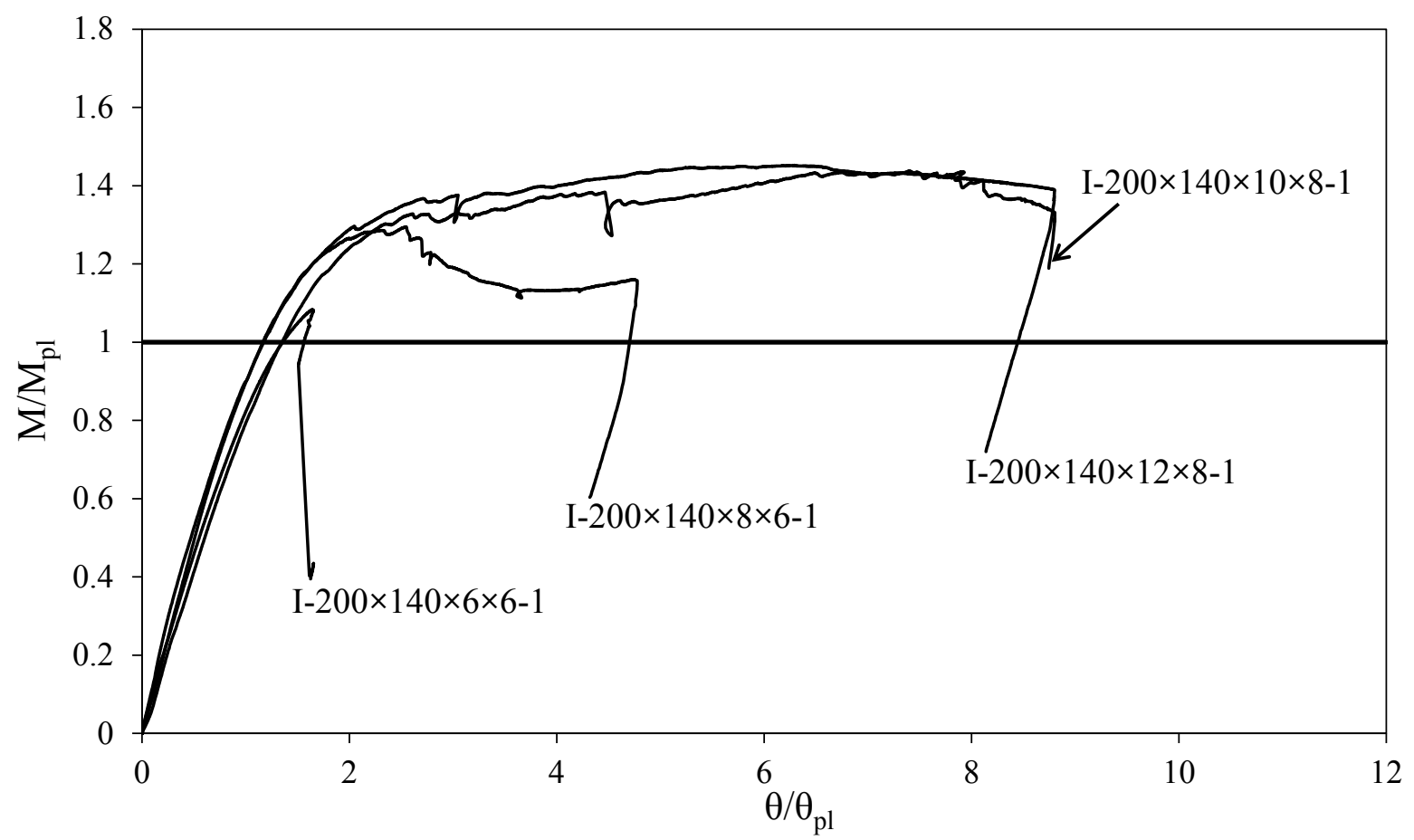

Fig. 17: Normalised moment-rotation curves for the tested sections under 3-point bending.

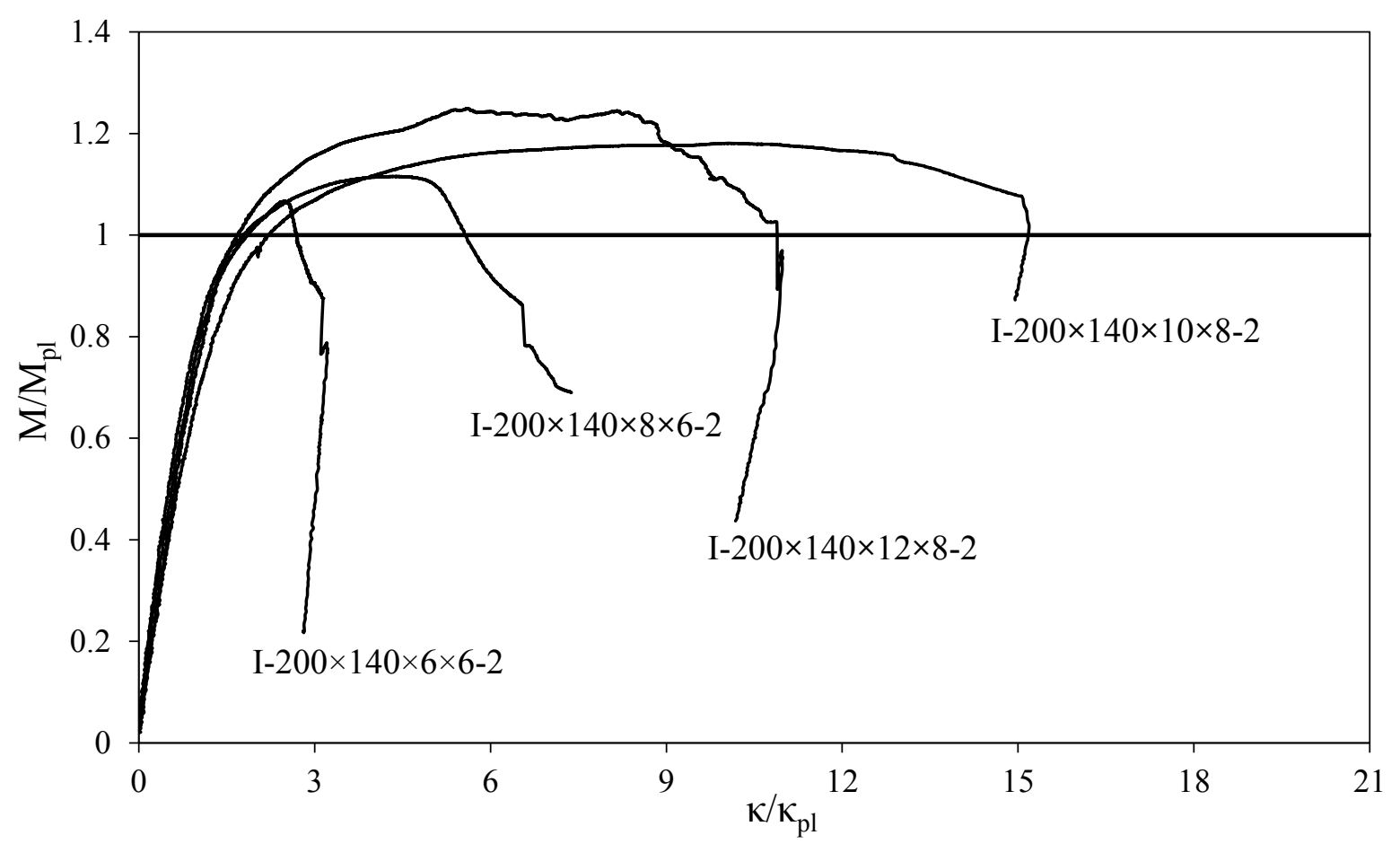

Fig. 18: Normalised moment-curvature curves for the tested sections under 4-point bending. 


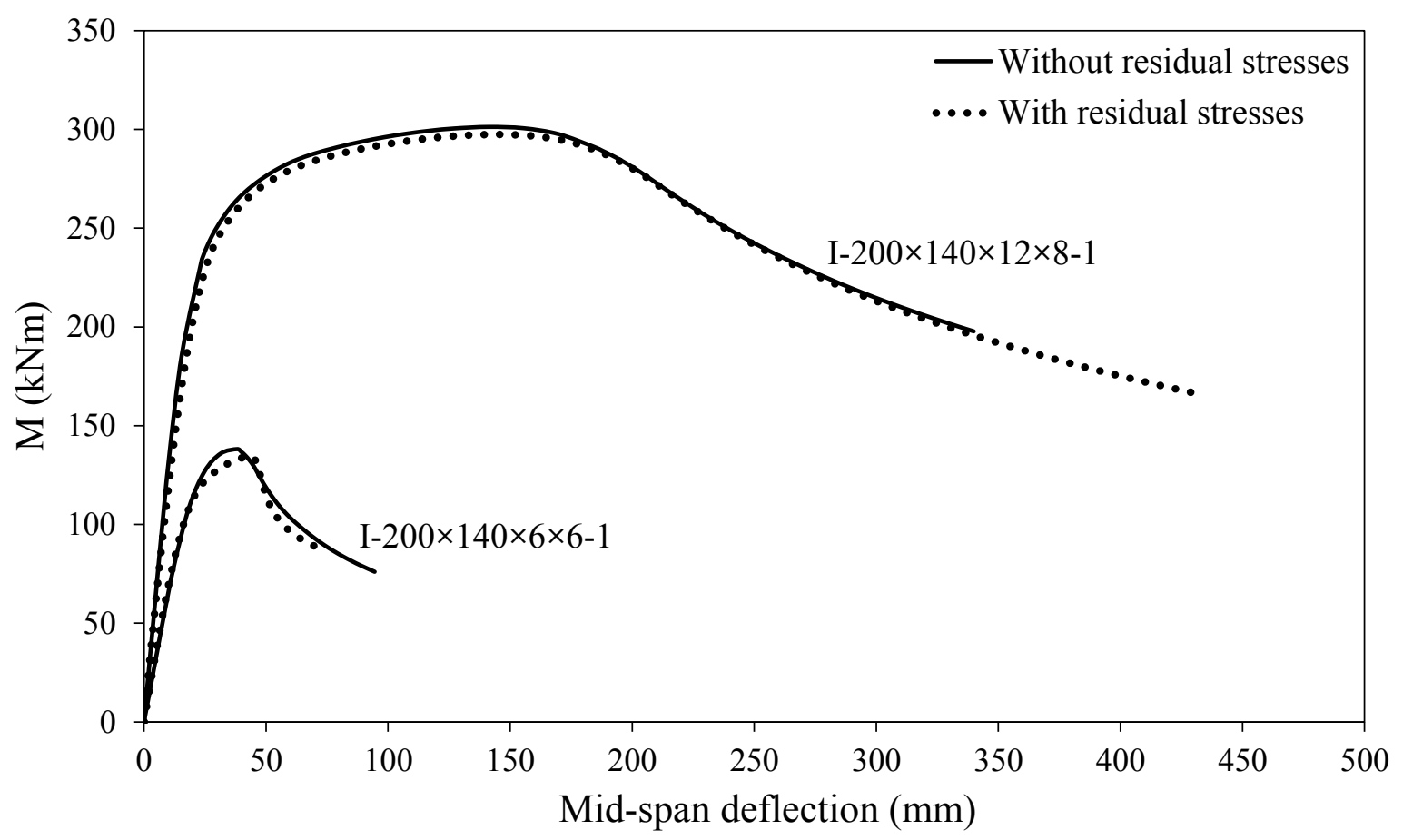

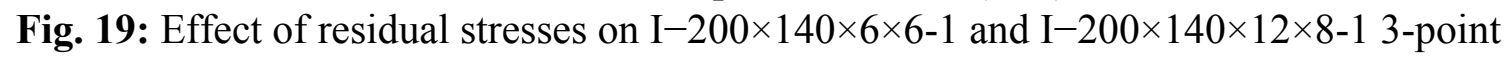
bending FE models.

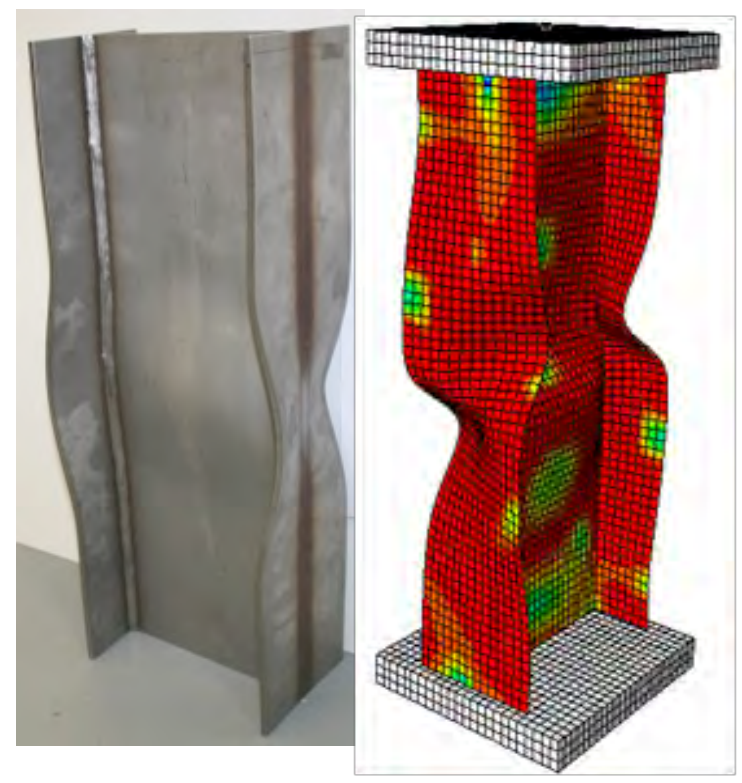

Fig. 20: Typical local buckling failure mode from the FE stub column models. 


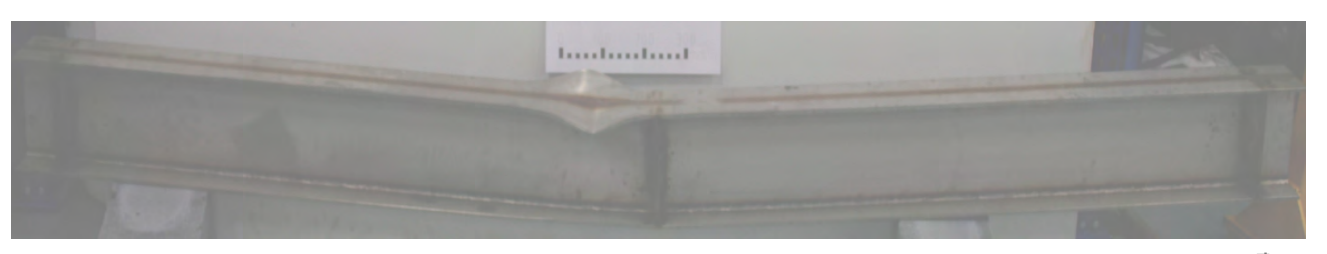

Fig. 21: Typical FE failure mode in the 3-point bending configuration.
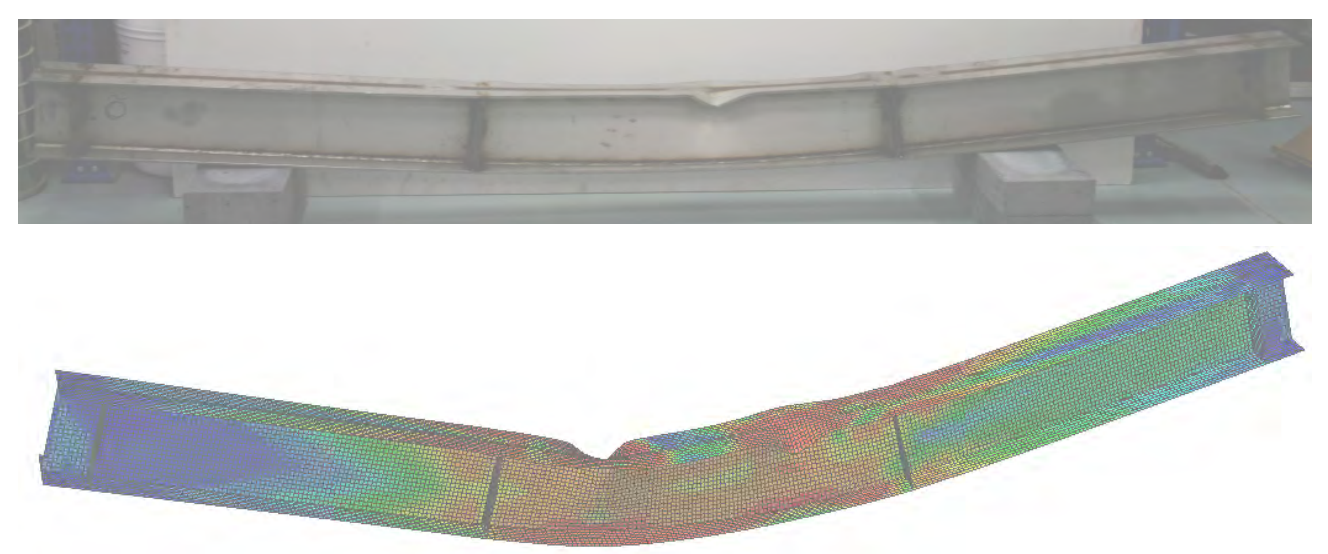

Fig. 22: Typical FE failure mode in the 4-point bending configuration.

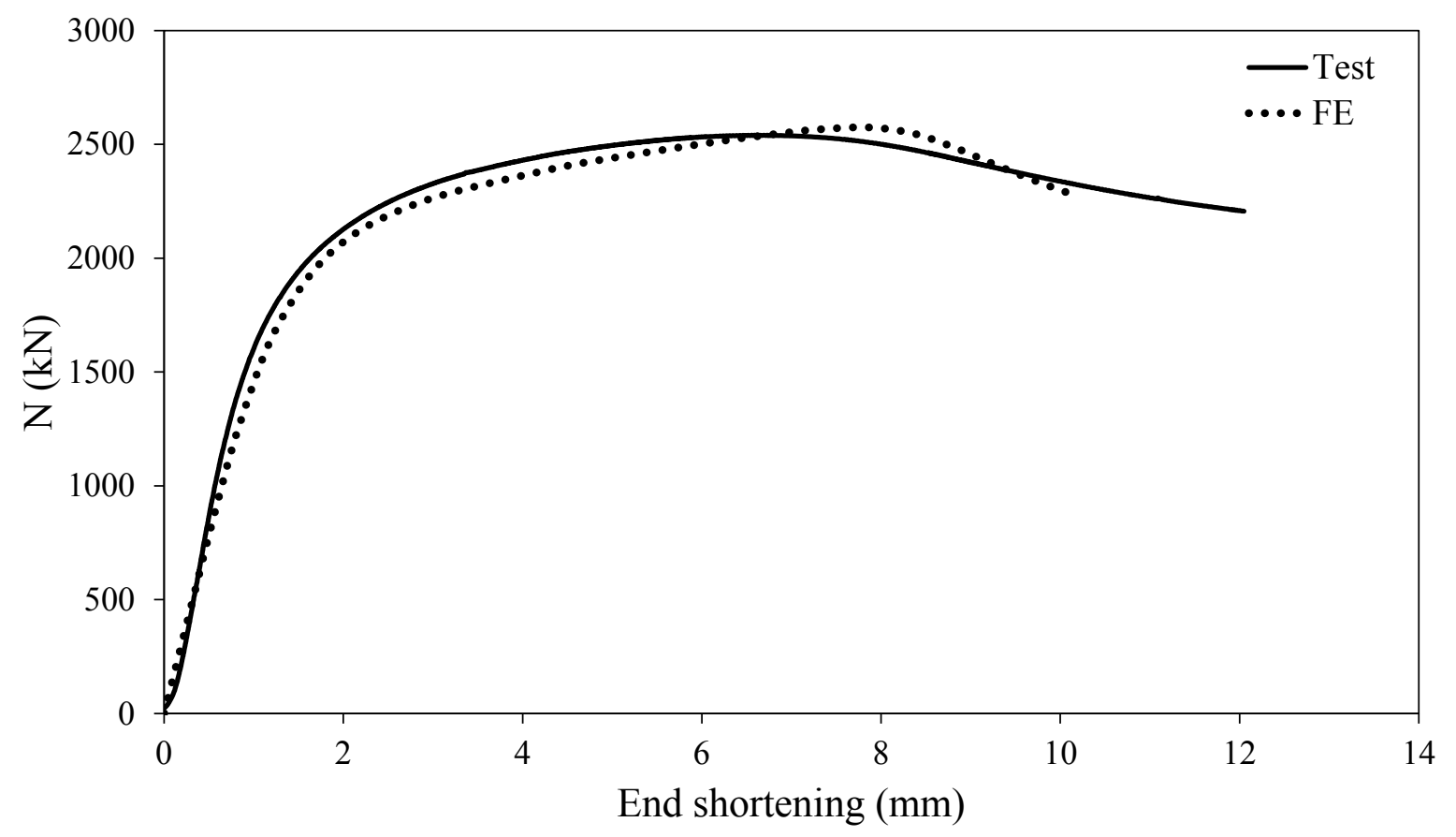

Fig. 23: Experimental and numerical load-end shortening curve for the stub column $\mathrm{I}-200 \times 140 \times 10 \times 8$. 


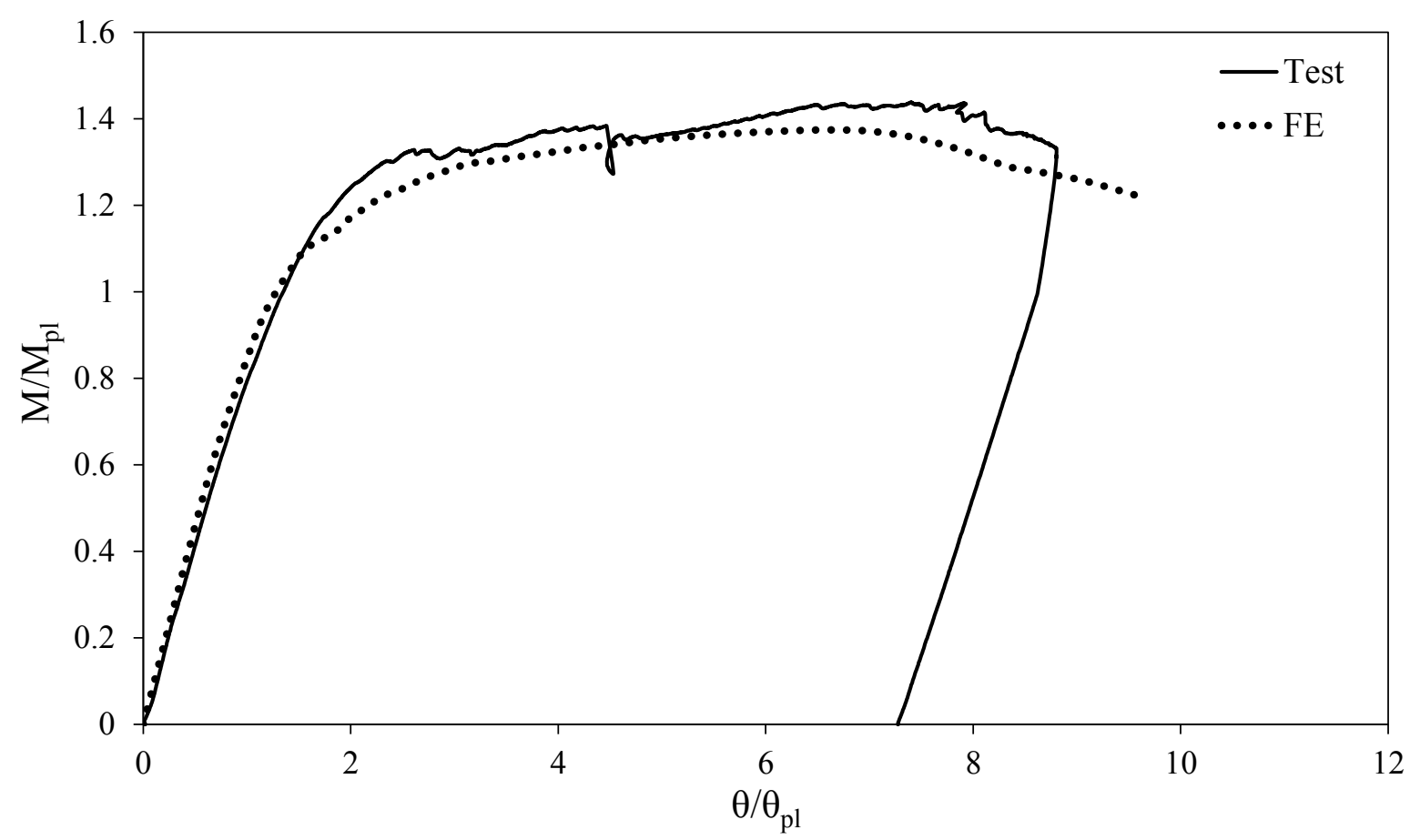

Fig. 24: Experimental and numerical normalised moment-rotation curve for the 3-point bending of $\mathrm{I}-200 \times 140 \times 10 \times 8-1$.

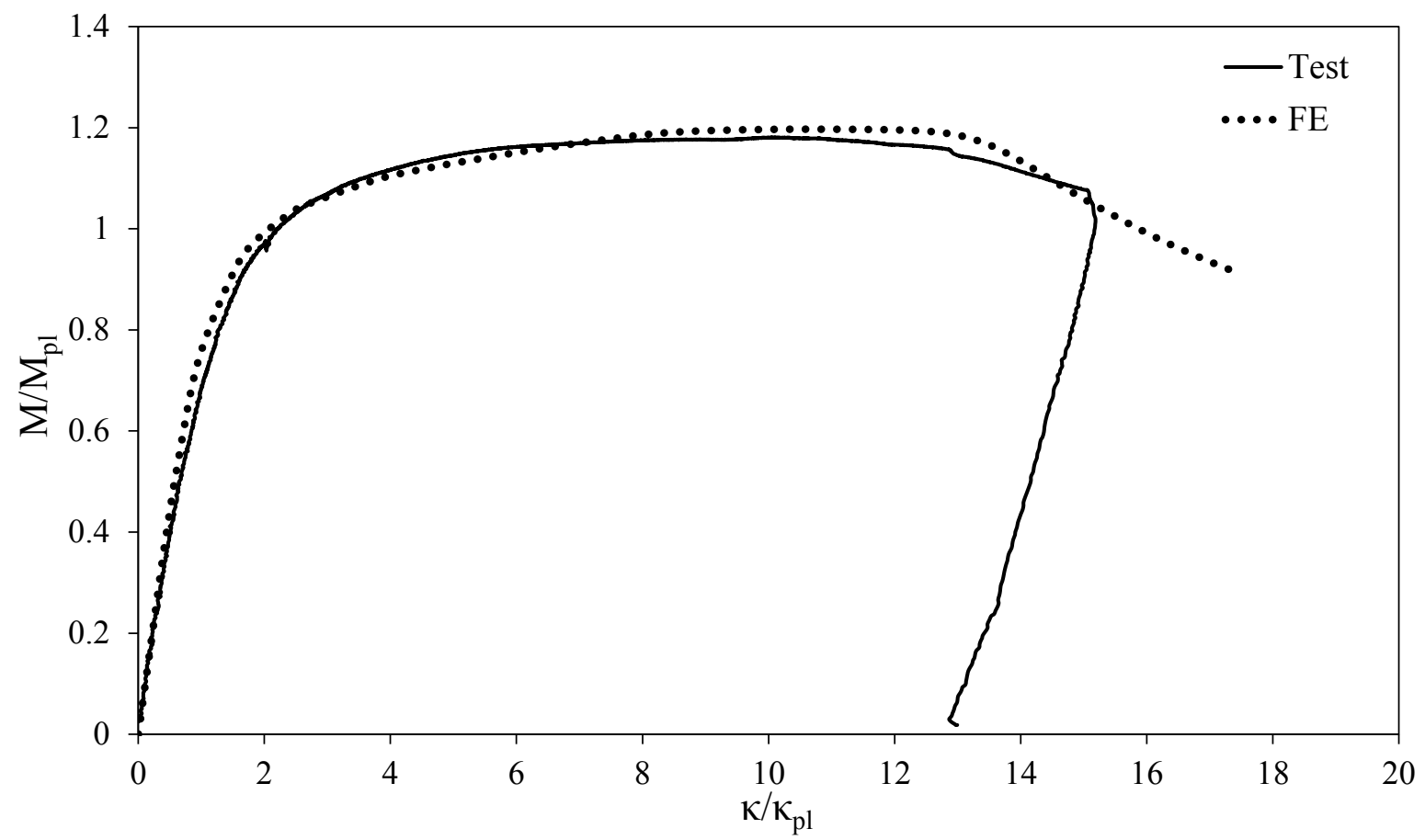

Fig. 25: Experimental and numerical normalised moment-curvature curve for the 4-point bending of I- $200 \times 140 \times 10 \times 8-2$. 


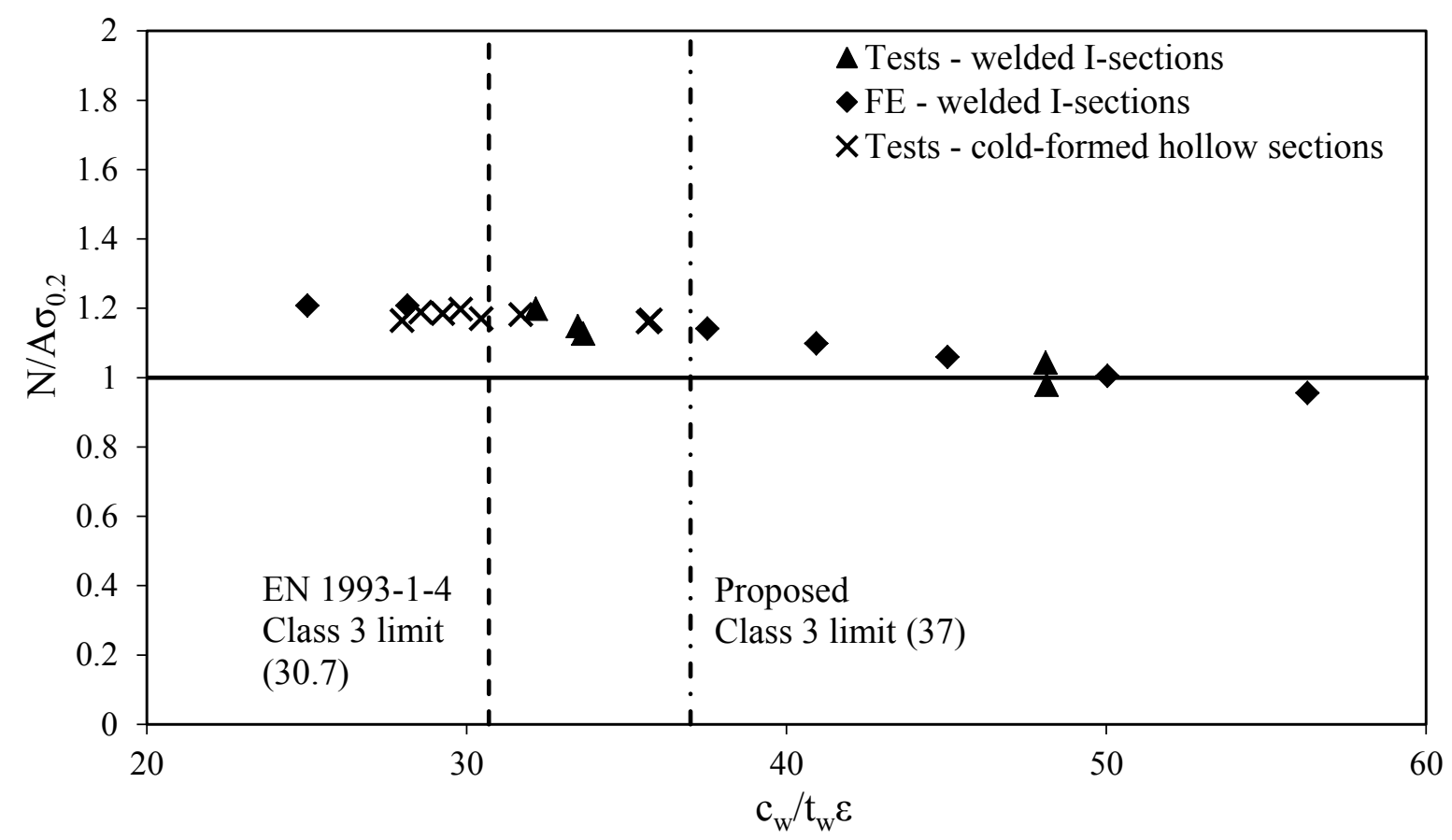

Fig. 26: Assessment of Class 3 slenderness limits for internal web elements in compression.

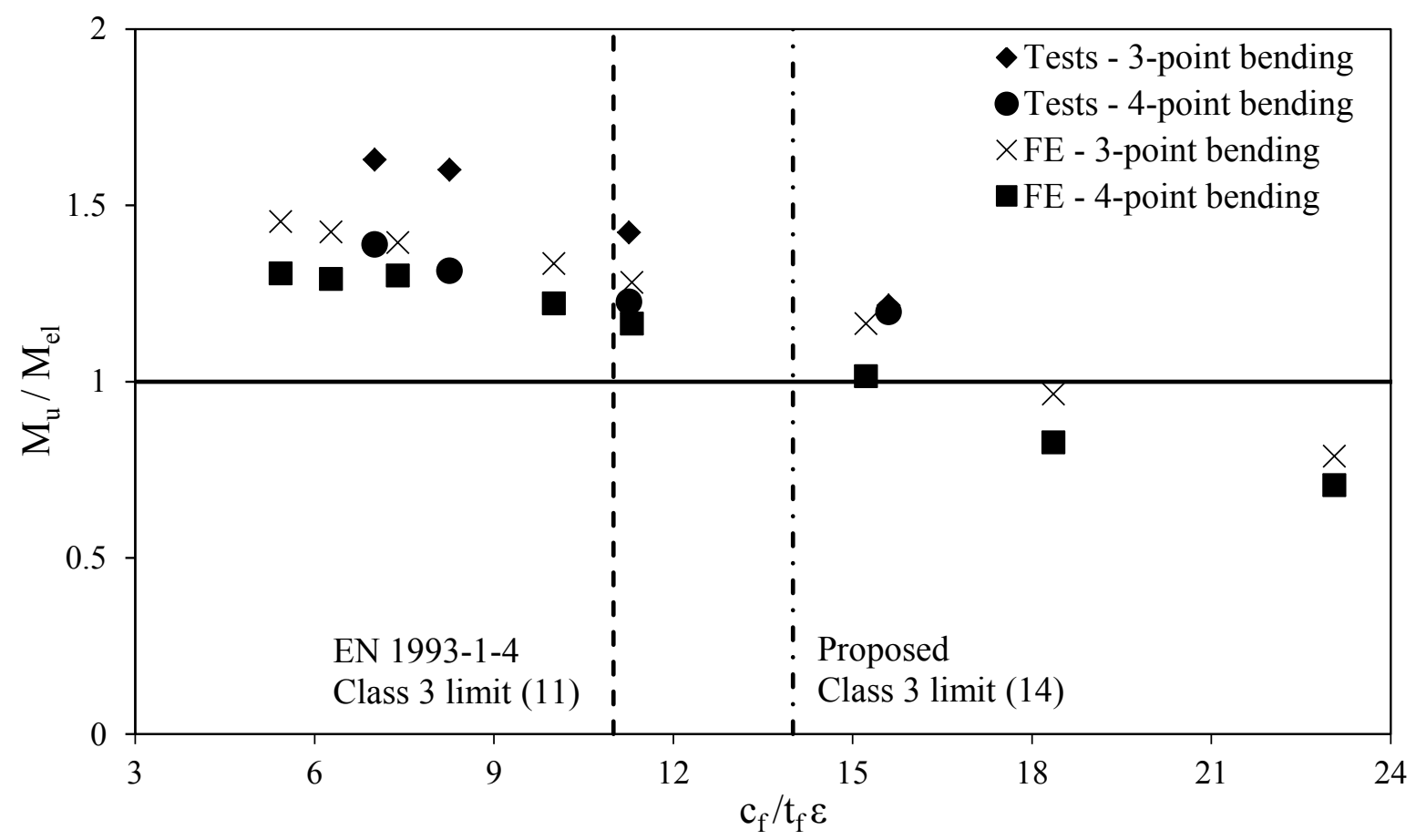

Fig. 27: Assessment of Class 3 slenderness limits for welded outstand flanges in compression. 


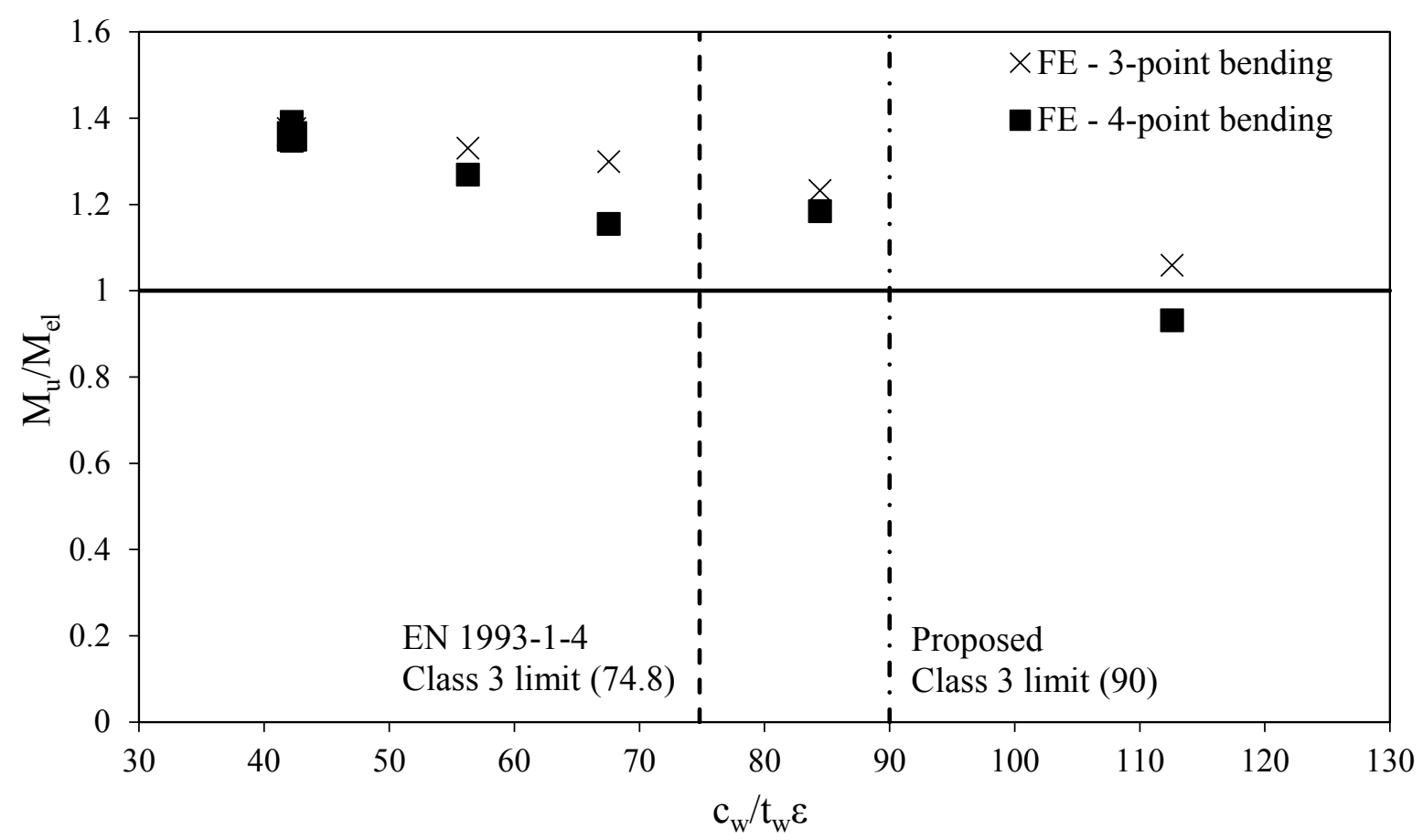

Fig. 28: Assessment of Class 3 slenderness limits for internal web elements in bending.

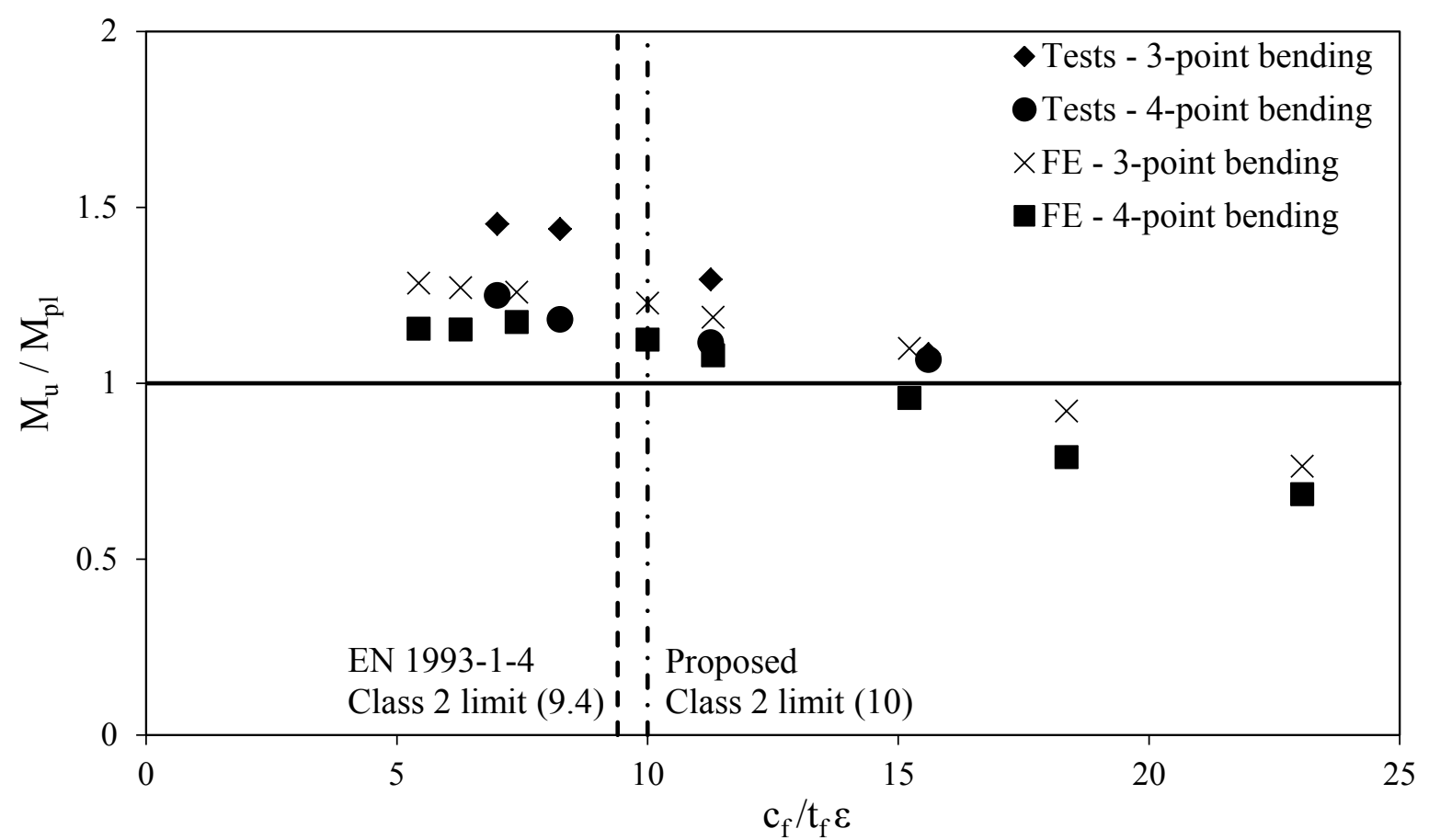

Fig. 29: Assessment of Class 2 slenderness limits for welded outstand flanges in compression. 


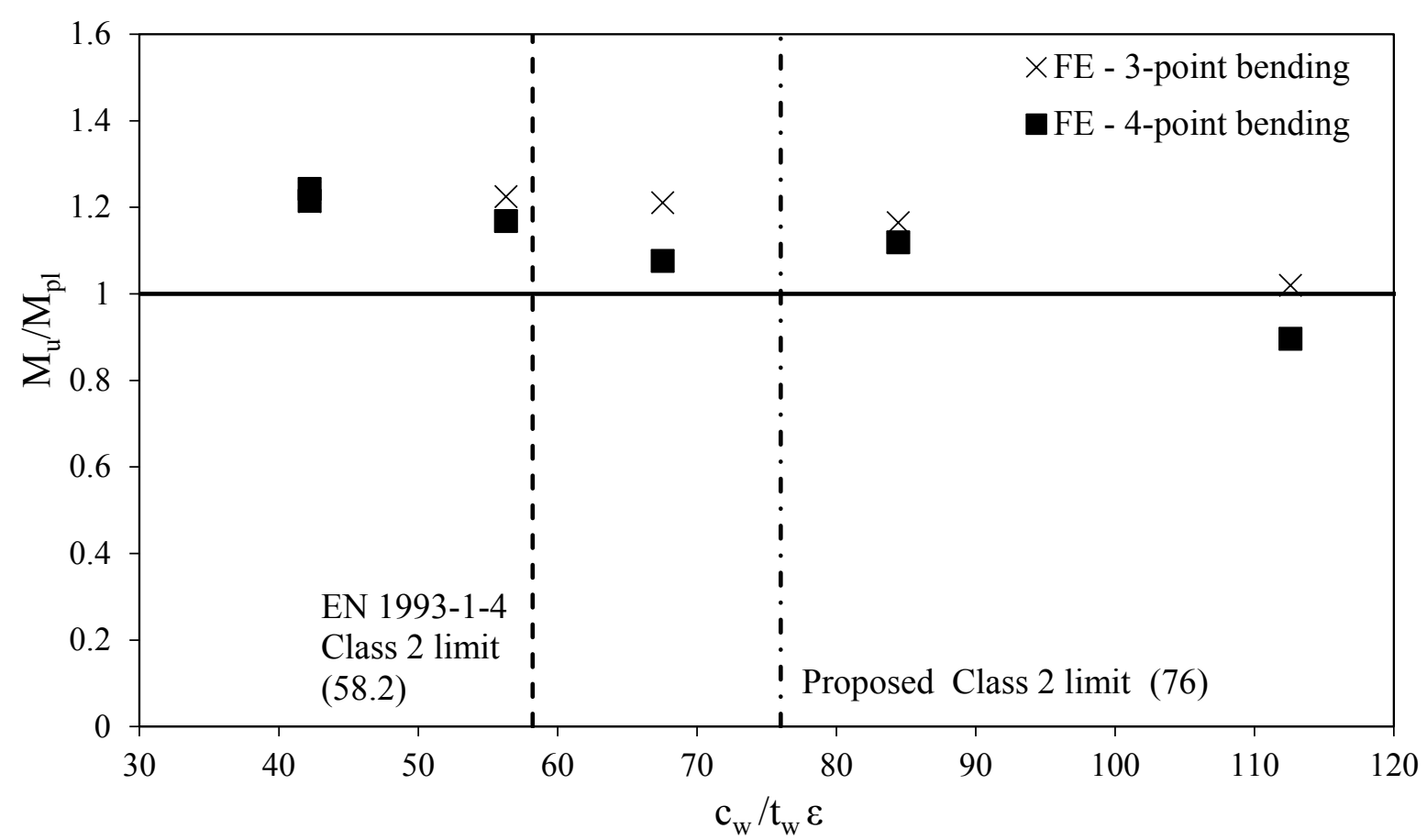

Fig. 30: Assessment of Class 2 slenderness limits for internal web elements in bending.

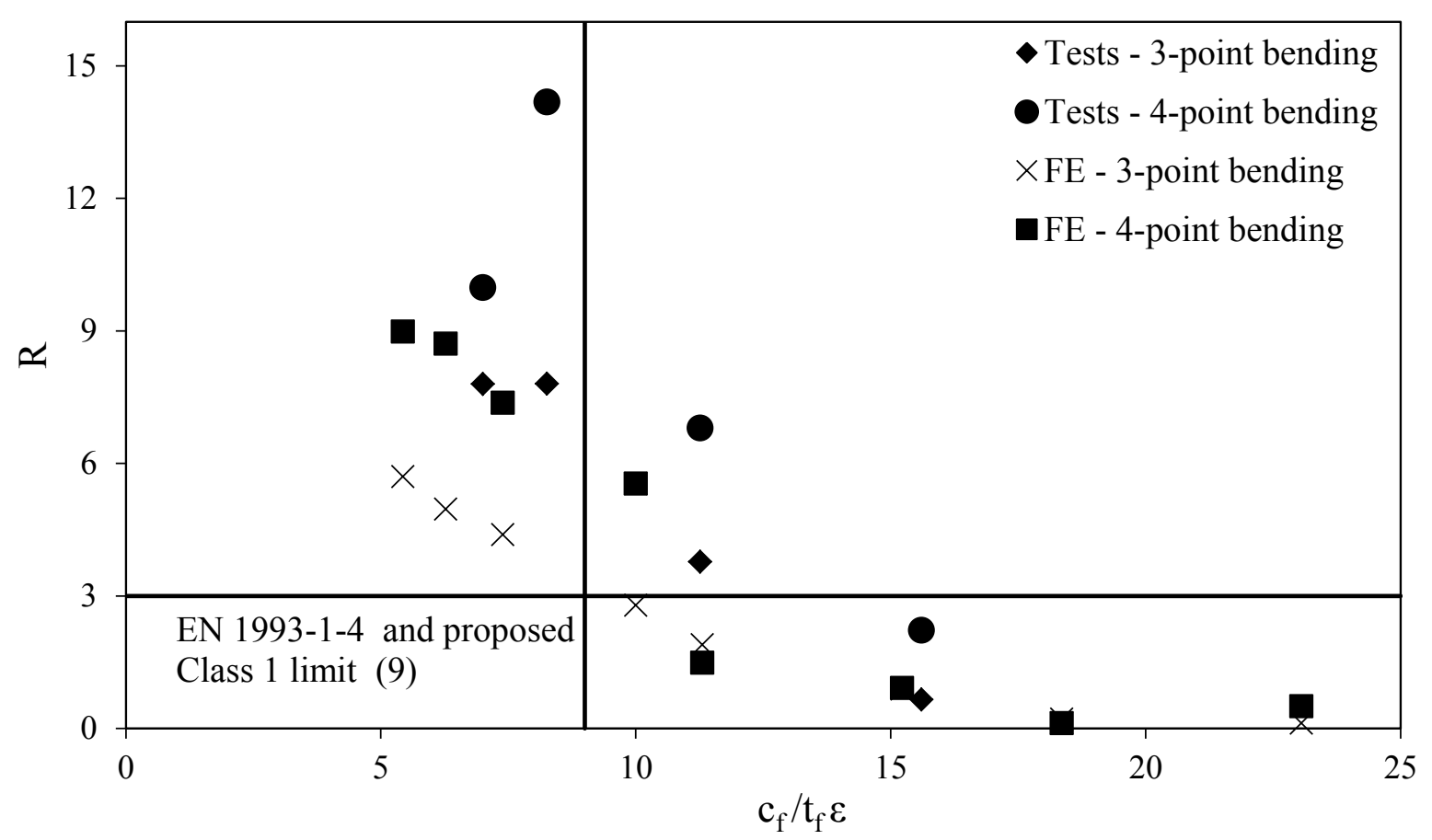

Fig. 31: Assessment of Class 1 slenderness limits for welded outstand flanges in compression. 


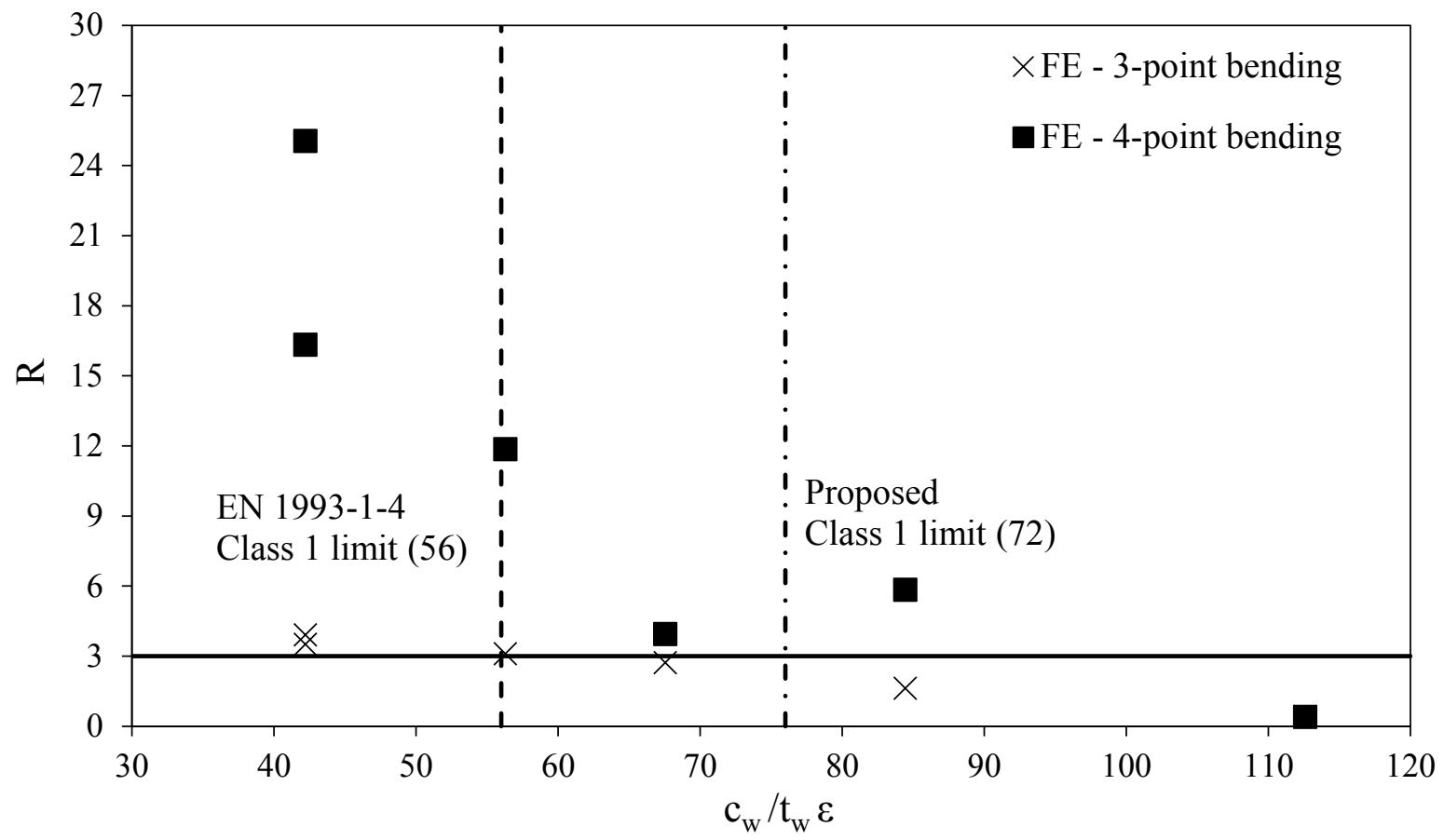

Fig. 32: Assessment of Class 1 slenderness limits for internal web elements in bending.

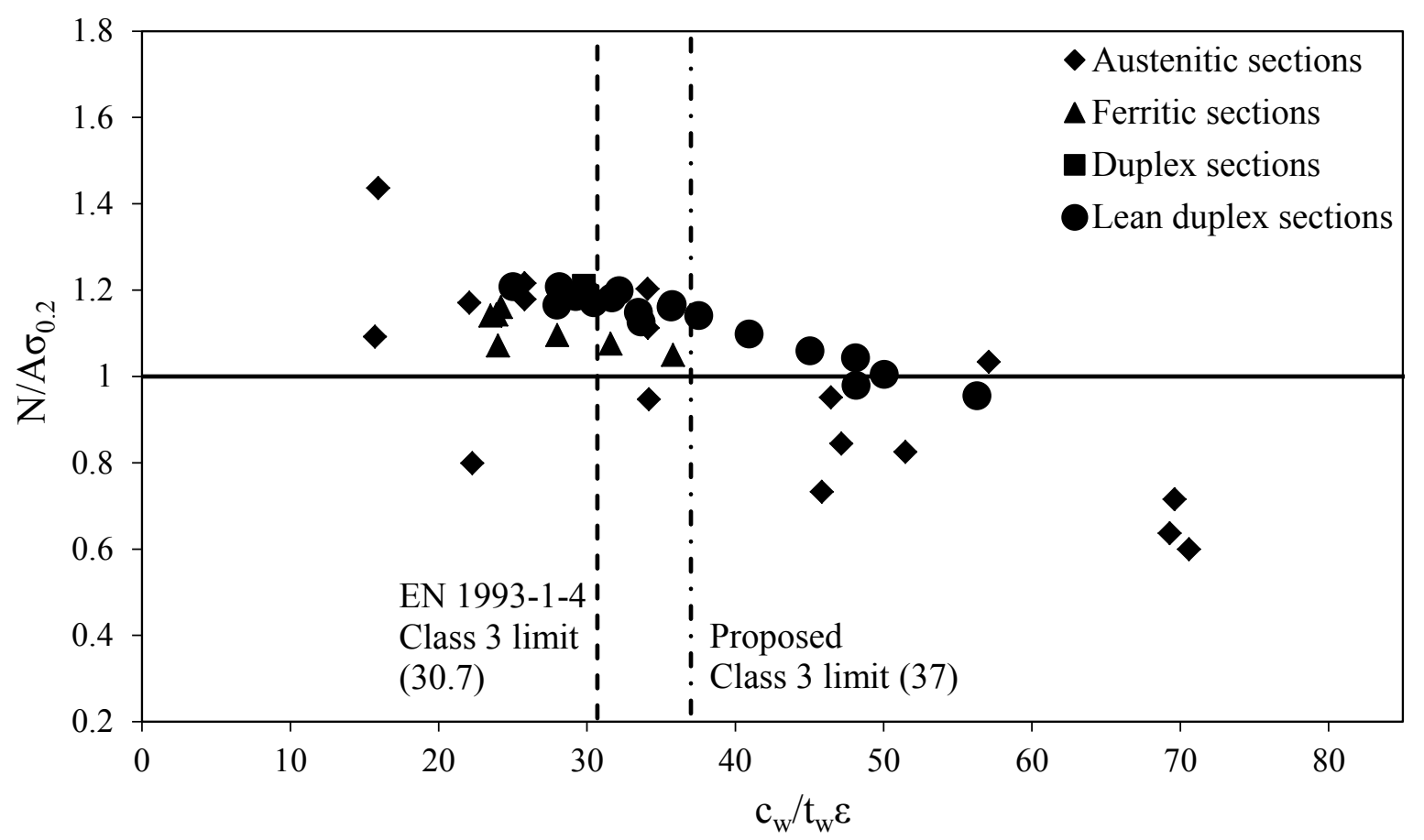

Fig. 33: Class 3 limits for internal compression elements - comparison between stainless steel grades. 


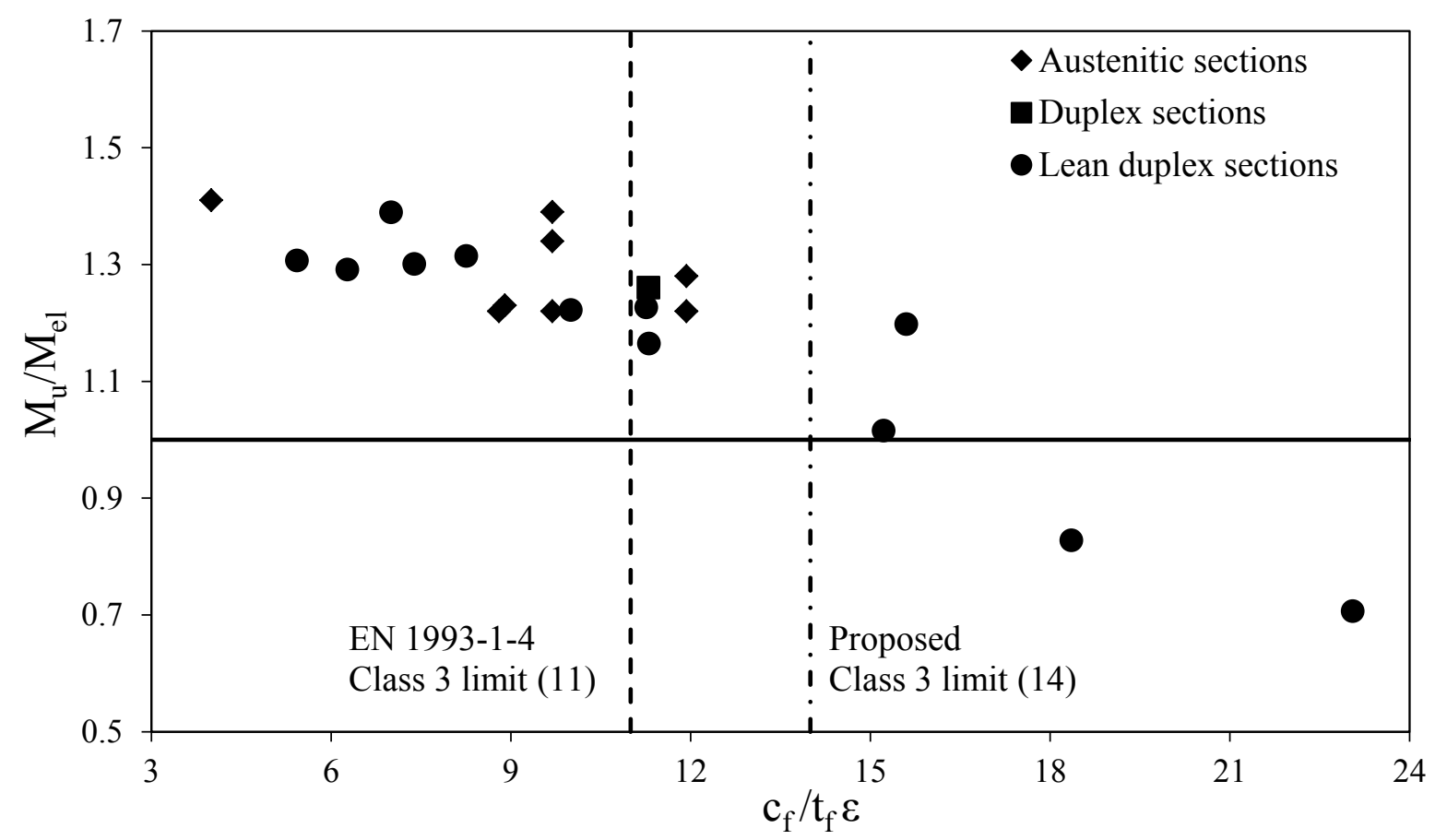

Fig. 34: Class 3 limits for welded outstand flanges - comparison between stainless steel grades.

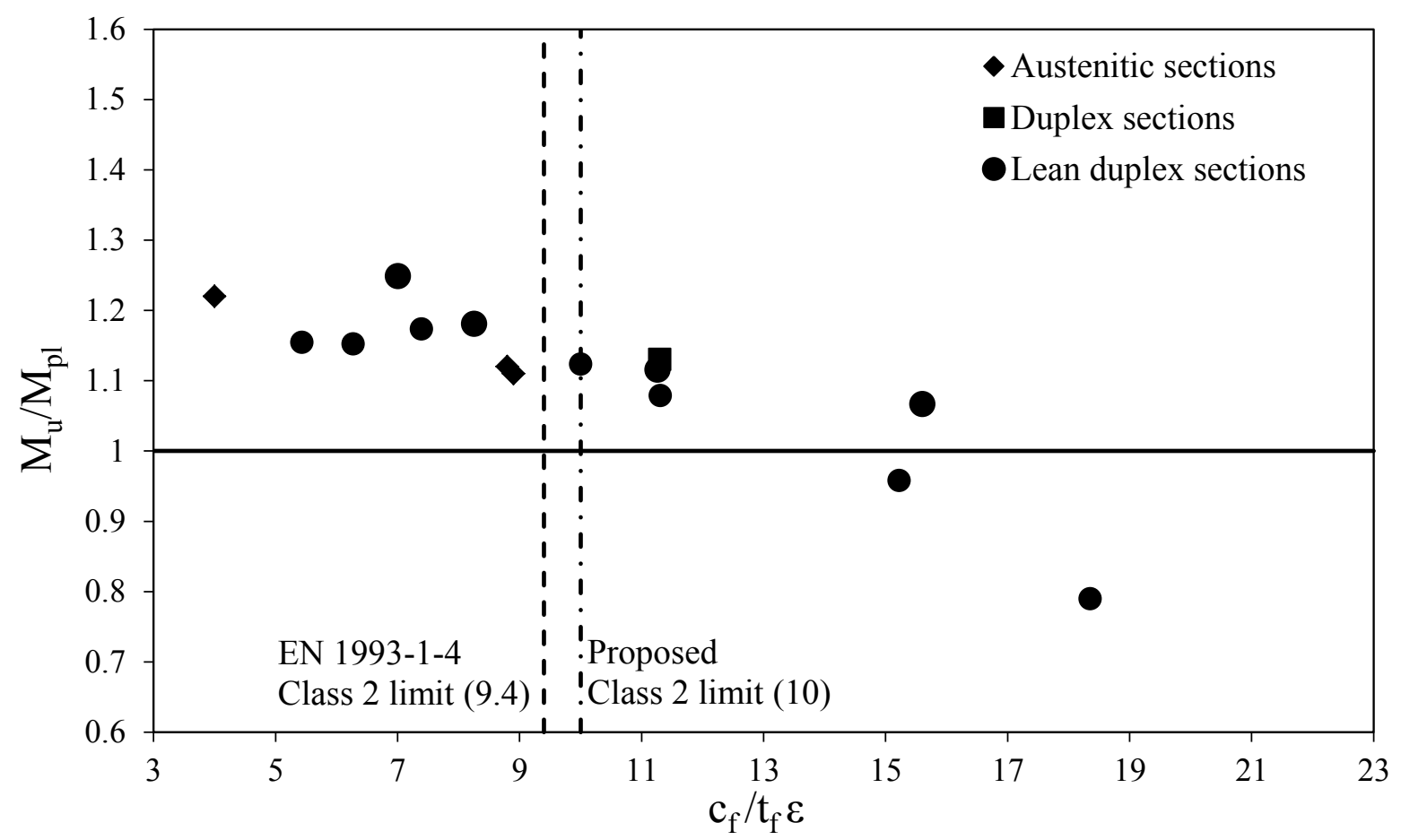

Fig. 35: Class 2 limits for welded outstand flanges - comparison between stainless steel grades. 
Table 1: Measured material properties from tensile coupon tests and mill certificates.

\begin{tabular}{|c|c|c|c|c|c|c|c|c|c|c|c|}
\hline \multirow{4}{*}{$\begin{array}{l}\text { Plate } \\
\text { thickness } \\
(\mathrm{mm})\end{array}$} & \multicolumn{8}{|c|}{ Tensile coupon tests } & \multirow{2}{*}{\multicolumn{3}{|c|}{$\begin{array}{l}\text { Mill certificate values } \\
\text { (transverse tension) }\end{array}$}} \\
\hline & \multirow{3}{*}{$\begin{array}{l}\text { Orientation to } \\
\text { rolling direction }\end{array}$} & \multirow{3}{*}{$\begin{array}{c}E \\
\left(\mathrm{~N} / \mathrm{mm}^{2}\right) \\
\end{array}$} & \multirow{3}{*}{$\begin{array}{c}\sigma_{0.2} \\
\left(\mathrm{~N} / \mathrm{mm}^{2}\right) \\
\end{array}$} & \multirow{3}{*}{$\begin{array}{c}\sigma_{1.0} \\
\left(\mathrm{~N} / \mathrm{mm}^{2}\right)\end{array}$} & \multirow{3}{*}{$\begin{array}{c}\sigma_{\mathrm{u}} \\
\left(\mathrm{N} / \mathrm{mm}^{2}\right)\end{array}$} & \multirow{3}{*}{$\begin{array}{c}\varepsilon_{\mathrm{f}} \\
(\%) \\
\end{array}$} & \multirow{2}{*}{\multicolumn{2}{|c|}{$\begin{array}{c}\text { Modified } \\
\text { R-O } \\
\text { coefficients } \\
\end{array}$}} & & & \\
\hline & & & & & & & & & \multirow{2}{*}{$\begin{array}{c}\sigma_{0.2} \\
\left(\mathrm{~N} / \mathrm{mm}^{2}\right) \\
\end{array}$} & \multirow{2}{*}{$\begin{array}{c}\sigma_{1.0} \\
\left(\mathrm{~N} / \mathrm{mm}^{2}\right) \\
\end{array}$} & \multirow{2}{*}{$\begin{array}{c}\sigma_{\mathrm{u}} \\
\left(\mathrm{N} / \mathrm{mm}^{2}\right) \\
\end{array}$} \\
\hline & & & & & & & $\mathrm{n}$ & $\mathrm{n}_{0.2,1.0}^{\prime}$ & & & \\
\hline 6.00 & Longitudinal (L1) & 192000 & 512 & 553 & 723 & 55 & 11.5 & 2.1 & 579 & 640 & 746 \\
\hline 6.02 & Longitudinal (L2) & 195000 & 520 & 562 & 732 & 52 & 9.9 & 2.2 & 579 & 640 & 746 \\
\hline 8.08 & Longitudinal (L1) & 196000 & 505 & 548 & 727 & 52 & 12.3 & 2.2 & 577 & 616 & 747 \\
\hline 8.07 & Longitudinal (L2) & 210000 & 503 & 543 & 728 & 50 & 12.0 & 2.2 & 577 & 616 & 747 \\
\hline 10.10 & Longitudinal (L1) & 215000 & 505 & 558 & 765 & 53 & 11.5 & 1.9 & 567 & 599 & 769 \\
\hline 10.08 & Longitudinal (L2) & 218000 & 497 & 556 & 772 & 49 & 12.0 & 2.5 & 567 & 599 & 769 \\
\hline 12.36 & Longitudinal (L1) & 197000 & 466 & -* & 734 & 38 & 11.0 & -* & 507 & 556 & 729 \\
\hline 12.42 & Longitudinal (L2) & 214000 & 447 & 506 & 711 & 57 & 10.0 & 2.4 & 507 & 556 & 729 \\
\hline
\end{tabular}

*Missing result due to testing problem

Table 2: Measured material properties from compressive coupon tests and mill certificates.

\begin{tabular}{|c|c|c|c|c|c|c|c|c|}
\hline \multirow{3}{*}{$\begin{array}{l}\text { Plate } \\
\text { thickness (mm) }\end{array}$} & \multicolumn{6}{|c|}{ Compressive coupon tests } & \multicolumn{2}{|c|}{$\begin{array}{l}\text { Mill certificate values (transverse } \\
\text { tension) }\end{array}$} \\
\hline & \multirow{2}{*}{$\begin{array}{l}\text { Orientation to } \\
\text { rolling direction }\end{array}$} & \multirow{2}{*}{$\begin{array}{c}E \\
\left(\mathrm{~N} / \mathrm{mm}^{2}\right)\end{array}$} & \multirow{2}{*}{$\begin{array}{c}\sigma_{0.2} \\
\left(\mathrm{~N} / \mathrm{mm}^{2}\right)\end{array}$} & \multirow{2}{*}{$\begin{array}{c}\sigma_{1.0} \\
\left(\mathrm{~N} / \mathrm{mm}^{2}\right)\end{array}$} & \multicolumn{2}{|c|}{$\begin{array}{c}\text { Modified } \\
\text { R-O } \\
\text { coefficients }\end{array}$} & \multirow{2}{*}{$\begin{array}{c}\sigma_{0.2} \\
\left(\mathrm{~N} / \mathrm{mm}^{2}\right)\end{array}$} & \multirow{2}{*}{$\begin{array}{c}\sigma_{1.0} \\
\left(\mathrm{~N} / \mathrm{mm}^{2}\right)\end{array}$} \\
\hline & & & & & $\mathrm{n}$ & $\mathrm{n}_{0.2,1.0}^{\prime}$ & & \\
\hline 5.99 & Transverse (T1) & 215000 & 561 & 624 & 11.7 & 2.0 & 579 & 640 \\
\hline 6.02 & Transverse (T2) & 212600 & 563 & 625 & 10.7 & 1.4 & 579 & 640 \\
\hline 6.02 & Longitudinal (L1) & 201400 & 493 & 576 & 7.9 & 1.9 & 579 & 640 \\
\hline 6.03 & Longitudinal (L2) & 196500 & 495 & 576 & 7.9 & 1.8 & 579 & 640 \\
\hline 8.08 & Transverse (T1) & 212000 & 562 & 622 & 10.4 & 1.6 & 577 & 616 \\
\hline 8.05 & Transverse (T2) & 215800 & 559 & 615 & 11.6 & 1.5 & 577 & 616 \\
\hline 8.10 & Longitudinal (L1) & 201900 & 489 & 567 & 7.1 & 1.8 & 577 & 616 \\
\hline 8.05 & Longitudinal (L2) & 197600 & 492 & 571 & 7.5 & 2.0 & 577 & 616 \\
\hline 10.04 & Transverse (T1) & 196300 & 507 & 581 & 6.4 & 1.5 & 567 & 599 \\
\hline 10.01 & Transverse (T2) & 203200 & 500 & 565 & 6.9 & 1.7 & 567 & 599 \\
\hline 9.99 & Longitudinal (L1) & 198900 & 473 & 543 & 7.9 & 1.6 & 567 & 599 \\
\hline 10.07 & Longitudinal (L2) & 205500 & 473 & 541 & 8.4 & 1.7 & 567 & 599 \\
\hline 12.35 & Transverse (T1) & 202700 & 490 & 557 & 7.8 & 1.6 & 507 & 556 \\
\hline 12.36 & Transverse (T2) & 200700 & 488 & 558 & 7.2 & 1.5 & 507 & 556 \\
\hline 12.35 & Longitudinal (L1) & 199700 & 460 & 532 & 8.1 & 1.8 & 507 & 556 \\
\hline 12.34 & Longitudinal (L2) & 194800 & 459 & 530 & 7.8 & 1.6 & 507 & 556 \\
\hline
\end{tabular}


Table 3: Measured geometric imperfection amplitudes.

\begin{tabular}{|l|c|c|c|}
\hline Specimen & $\omega_{\text {flangel }}(\mathrm{mm})$ & $\omega_{\text {flange }}(\mathrm{mm})$ & $\omega_{\text {web }}(\mathrm{mm})$ \\
\hline $\mathrm{I}-200 \times 140 \times 6 \times 6-1$ & 0.107 & 0.151 & 0.164 \\
\hline $\mathrm{I}-200 \times 140 \times 6 \times 6-2$ & 0.495 & 0.426 & 0.241 \\
\hline $\mathrm{I}-200 \times 140 \times 8 \times 6-1$ & 0.222 & 0.120 & 0.401 \\
\hline $\mathrm{I}-200 \times 140 \times 8 \times 6-2$ & 0.125 & 0.120 & 0.284 \\
\hline $\mathrm{I}-200 \times 140 \times 10 \times 8-1$ & 0.149 & 0.195 & 0.326 \\
\hline $\mathrm{I}-200 \times 140 \times 10 \times 8-2$ & 0.125 & 0.270 & 0.489 \\
\hline $\mathrm{I}-200 \times 140 \times 12 \times 8-1$ & 0.272 & 0.300 & 0.259 \\
\hline $\mathrm{I}-200 \times 140 \times 12 \times 8-2$ & 0.132 & 0.174 & 0.154 \\
\hline
\end{tabular}

Table 4: Stub column test data.

\begin{tabular}{|l|c|c|c|c|c|c|c|}
\hline Specimen & $\mathrm{L}(\mathrm{mm})$ & $\mathrm{b}(\mathrm{mm})$ & $\mathrm{h}(\mathrm{mm})$ & $\mathrm{t}_{\mathrm{f}}(\mathrm{mm})$ & $\mathrm{t}_{\mathrm{w}}(\mathrm{mm})$ & $\mathrm{A}\left(\mathrm{mm}^{2}\right)$ & $\mathrm{N}_{\mathrm{u}}(\mathrm{kN})$ \\
\hline $\mathrm{I}-200 \times 140 \times 6 \times 6$ & 600.35 & 138.90 & 202.05 & 6.12 & 6.01 & 2914.3 & 1473 \\
\hline $\mathrm{I}-200 \times 140 \times 8 \times 6$ & 600.33 & 139.00 & 201.06 & 8.04 & 5.98 & 3438.1 & 1849 \\
\hline $\mathrm{I}-200 \times 140 \times 10 \times 8$ & 600.28 & 139.00 & 199.15 & 10.35 & 8.03 & 4476.4 & 2540 \\
\hline $\mathrm{I}-200 \times 140 \times 12 \times 8$ & 600.15 & 139.30 & 199.13 & 12.68 & 8.14 & 5153.3 & 2978 \\
\hline
\end{tabular}

Table 5: Dimensions of the tested cross-sections under 3-point bending.

\begin{tabular}{|l|c|c|c|c|c|}
\hline Specimen & $\begin{array}{c}\text { Depth, h } \\
(\mathrm{mm})\end{array}$ & $\begin{array}{c}\text { Flange } \\
\text { width, } \mathrm{b} \\
(\mathrm{mm})\end{array}$ & $\begin{array}{c}\text { Flange } \\
\text { thickness, } \mathrm{t}_{\mathrm{f}} \\
(\mathrm{mm})\end{array}$ & $\begin{array}{c}\text { Web } \\
\text { thickness, } \mathrm{t}_{\mathrm{w}} \\
(\mathrm{mm})\end{array}$ & $\begin{array}{c}\text { Weld throat, a } \\
(\mathrm{mm})\end{array}$ \\
\hline $\mathrm{I}-200 \times 140 \times 6 \times 6-1$ & 202.05 & 138.89 & 6.12 & 6.01 & 5.00 \\
\hline $\mathrm{I}-200 \times 140 \times 8 \times 6-1$ & 200.17 & 139.04 & 8.11 & 6.03 & 5.00 \\
\hline $\mathrm{I}-200 \times 140 \times 10 \times 8-1$ & 198.72 & 139.00 & 10.18 & 8.00 & 6.00 \\
\hline $\mathrm{I}-200 \times 140 \times 12 \times 8-1$ & 199.00 & 139.29 & 12.54 & 8.05 & 6.00 \\
\hline
\end{tabular}

Table 6: Summary of key test results from 3-point bending.

\begin{tabular}{|l|c|c|c|c|c|c|}
\hline Specimen & $\mathrm{M}_{\mathrm{el}}(\mathrm{kNm})$ & $\mathrm{M}_{\mathrm{pl}}(\mathrm{kNm})$ & $\mathrm{M}_{\mathrm{u}}(\mathrm{kNm})$ & $\theta_{\mathrm{pl}}(\mathrm{rad})$ & $\theta_{\mathrm{u}}(\mathrm{rad})$ & $\mathrm{R}$ \\
\hline $\mathrm{I}-200 \times 140 \times 6 \times 6-1$ & 111 & 124 & 134 & 0.0384 & 0.0640 & 0.67 \\
\hline $\mathrm{I}-200 \times 140 \times 8 \times 6-1$ & 137 & 151 & 195 & 0.0354 & 0.169 & 3.77 \\
\hline $\mathrm{I}-200 \times 140 \times 10 \times 8-1$ & 165 & 183 & 264 & 0.0317 & 0.279 & 7.80 \\
\hline $\mathrm{I}-200 \times 140 \times 12 \times 8-1$ & 187 & 210 & 305 & 0.0316 & 0.278 & 7.80 \\
\hline
\end{tabular}


Table 7: Dimensions of the tested cross-sections under 4-point bending.

\begin{tabular}{|l|c|c|c|c|c|}
\hline Specimen & $\begin{array}{c}\text { Depth, } h \\
(\mathrm{~mm})\end{array}$ & $\begin{array}{c}\text { Flange } \\
\text { width, } \mathrm{b} \\
(\mathrm{mm})\end{array}$ & $\begin{array}{c}\text { Flange } \\
\text { thickness, } \mathrm{t}_{\mathrm{f}} \\
(\mathrm{mm})\end{array}$ & $\begin{array}{c}\text { Web } \\
\text { thickness, } \\
(\mathrm{mm})\end{array}$ & $\begin{array}{c}\text { Weld throat, a } \\
(\mathrm{mm})\end{array}$ \\
\hline $\mathrm{I}-200 \times 140 \times 6 \times 6-1$ & 202.05 & 138.60 & 6.11 & 6.01 & 5.00 \\
\hline $\mathrm{I}-200 \times 140 \times 8 \times 6-1$ & 200.60 & 139.30 & 8.11 & 6.06 & 5.00 \\
\hline $\mathrm{I}-200 \times 140 \times 10 \times 8-1$ & 199.27 & 139.00 & 10.26 & 7.99 & 6.00 \\
\hline $\mathrm{I}-200 \times 140 \times 12 \times 8-1$ & 198.87 & 139.64 & 12.32 & 8.07 & 6.00 \\
\hline
\end{tabular}

Table 8: Summary of key test results from 4-point bending.

\begin{tabular}{|l|c|c|c|c|c|c|}
\hline Specimen & $\mathrm{M}_{\mathrm{el}}(\mathrm{kNm})$ & $\mathrm{M}_{\mathrm{pl}}(\mathrm{kNm})$ & $\mathrm{M}_{\mathrm{u}}(\mathrm{kNm})$ & $\kappa_{\mathrm{pl}}\left(\mathrm{mm}^{-1}\right)$ & $\kappa_{\mathrm{u}}\left(\mathrm{mm}^{-1}\right)$ & $\mathrm{R}$ \\
\hline $\mathrm{I}-200 \times 140 \times 6 \times 6-2$ & 110 & 124 & 132 & $2.74 \times 10^{-5}$ & $8.84 \times 10^{-5}$ & 2.22 \\
\hline $\mathrm{I}-200 \times 140 \times 8 \times 6-2$ & 138 & 151 & 169 & $2.53 \times 10^{-5}$ & 0.000197 & 6.79 \\
\hline $\mathrm{I}-200 \times 140 \times 10 \times 8-2$ & 166 & 185 & 219 & $2.26 \times 10^{-5}$ & 0.000343 & 14.20 \\
\hline $\mathrm{I}-200 \times 140 \times 12 \times 8-2$ & 186 & 207 & 259 & $2.234 \times 10^{-5}$ & 0.000245 & 9.98 \\
\hline
\end{tabular}

Table 9: Comparison of the laboratory test results with FE results for varying imperfection amplitudes.

\begin{tabular}{|c|c|c|c|c|c|}
\hline & & & Imperfectio & amplitude & \\
\hline \multirow[t]{2}{*}{ Test type } & \multirow[t]{2}{*}{ Specimen } & Measured amplitude & $t / 100$ & $\mathrm{t} / 1000$ & $\begin{array}{c}\text { Dawson and Walker } \\
\omega_{\mathrm{D} \& \mathrm{~W}}\end{array}$ \\
\hline & & FE $\mathrm{N}_{\mathrm{u}} /$ Test $\mathrm{N}_{\mathrm{u}}$ & FE $N_{u} /$ Test $N_{u}$ & FE $N_{u} /$ Test $N_{u}$ & FE $N_{u} /$ Test $N_{u}$ \\
\hline \multirow{4}{*}{ Stub column } & $\mathrm{I}-200 \times 140 \times 6 \times 6$ & 0.88 & 0.90 & 1.04 & 0.93 \\
\hline & $\mathrm{I}-200 \times 140 \times 8 \times 6$ & 0.93 & 0.94 & 1.02 & 0.94 \\
\hline & $\mathrm{I}-200 \times 140 \times 10 \times 8$ & 1.01 & 1.00 & 1.02 & 0.95 \\
\hline & I- $200 \times 140 \times 12 \times 8$ & 0.98 & 0.97 & 0.99 & 0.93 \\
\hline \multirow{4}{*}{ 3-point bending } & $\mathrm{I}-200 \times 140 \times 6 \times 6-1$ & 1.06 & 1.04 & 1.08 & 1.04 \\
\hline & $\mathrm{I}-200 \times 140 \times 8 \times 6-1$ & 0.94 & 0.94 & 0.94 & 0.94 \\
\hline & $\mathrm{I}-200 \times 140 \times 10 \times 8-1$ & 0.93 & 0.93 & 0.93 & 0.93 \\
\hline & $\mathrm{I}-200 \times 140 \times 12 \times 8-1$ & 0.92 & 0.95 & 0.95 & 0.95 \\
\hline \multirow{4}{*}{ 4-point bending } & $\mathrm{I}-200 \times 140 \times 6 \times 6-2$ & 1.02 & 1.02 & 1.02 & 1.02 \\
\hline & $\mathrm{I}-200 \times 140 \times 8 \times 6-2$ & 1.03 & 1.03 & 1.03 & 1.03 \\
\hline & $\mathrm{I}-200 \times 140 \times 10 \times 8-2$ & 1.01 & 1.01 & 1.01 & 1.01 \\
\hline & $\mathrm{I}-200 \times 140 \times 12 \times 8-2$ & 0.90 & 0.93 & 0.93 & 0.93 \\
\hline Mean & & 0.97 & 0.97 & 1.00 & 0.97 \\
\hline $\mathrm{COV}$ & & 0.06 & 0.05 & 0.05 & 0.05 \\
\hline
\end{tabular}


Table 10: Eurocode 3 slenderness limits for carbon steel (CS), stainless steel (SS) and proposed limits for stainless steel compression elements.

\begin{tabular}{|c|c|c|c|c|c|c|c|c|c|}
\hline \multirow[b]{2}{*}{ Element } & \multicolumn{3}{|c|}{ Class 1} & \multicolumn{3}{|c|}{ Class 2} & \multicolumn{3}{|c|}{ Class 3} \\
\hline & $\begin{array}{c}\text { CS limit } \\
{[37]}\end{array}$ & $\begin{array}{c}\text { SS limit } \\
{[7]}\end{array}$ & $\begin{array}{c}\text { Proposed limit } \\
{[36]}\end{array}$ & $\begin{array}{c}\text { CS limit } \\
{[37]}\end{array}$ & $\begin{array}{c}\text { SS limit } \\
{[7]}\end{array}$ & $\begin{array}{c}\text { Proposed limit } \\
{[36]}\end{array}$ & $\begin{array}{c}\text { CS limit } \\
{[37]}\end{array}$ & $\begin{array}{c}\text { SS limit } \\
{[7]}\end{array}$ & $\begin{array}{c}\text { Proposed limit } \\
{[36]}\end{array}$ \\
\hline $\begin{array}{l}\text { Internal element } \\
\text { in compression }\end{array}$ & $33 \varepsilon$ & $25.7 \varepsilon$ & $33 \varepsilon$ & $38 \varepsilon$ & $26.7 \varepsilon$ & $35 \varepsilon$ & $42 \varepsilon$ & $30.7 \varepsilon$ & $37 \varepsilon$ \\
\hline $\begin{array}{l}\text { Internal element } \\
\text { in bending }\end{array}$ & $72 \varepsilon$ & $56 \varepsilon$ & $72 \varepsilon$ & $83 \varepsilon$ & $58.2 \varepsilon$ & $76 \varepsilon$ & $124 \varepsilon$ & $74.8 \varepsilon$ & $90 \varepsilon$ \\
\hline $\begin{array}{l}\text { Welded outstand } \\
\text { element in compression }\end{array}$ & $9 \varepsilon$ & $9 \varepsilon$ & $9 \varepsilon$ & $10 \varepsilon$ & $9.4 \varepsilon$ & $10 \varepsilon$ & $14 \varepsilon$ & $11 \varepsilon$ & $14 \varepsilon$ \\
\hline
\end{tabular}


Table 11: Comparison between test (and FE) results and predicted capacities from EN 1993-1-4, En 1993-1-4 with revised slenderness limits and the CSM.

\begin{tabular}{|c|c|c|c|c|}
\hline Test type & Specimen designation & EC3/Test & Proposed/Test & CSM/Test \\
\hline \multirow{4}{*}{ Stub column tests } & $\mathrm{I}-200 \times 140 \times 6 \times 6$ & 0.91 & 0.93 & - \\
\hline & $\mathrm{I}-200 \times 140 \times 8 \times 6$ & 0.92 & 0.96 & - \\
\hline & $\mathrm{I}-200 \times 140 \times 10 \times 8$ & 0.88 & 0.88 & 0.90 \\
\hline & $\mathrm{I}-200 \times 140 \times 12 \times 8$ & 0.86 & 0.86 & 0.88 \\
\hline \multirow{8}{*}{$\begin{array}{l}\text { Stub column FE } \\
\text { models }\end{array}$} & $\mathrm{I}-200 \times 140 \times 8 \times 4.8$ & 0.84 & 0.85 & - \\
\hline & $\mathrm{I}-200 \times 140 \times 9 \times 5.4$ & 0.81 & 0.82 & - \\
\hline & $\mathrm{I}-200 \times 140 \times 10 \times 6$ & 0.78 & 0.79 & - \\
\hline & $\mathrm{I}-200 \times 140 \times 11 \times 6.6$ & 0.76 & 0.78 & - \\
\hline & $\mathrm{I}-200 \times 140 \times 12 \times 7.2$ & 0.74 & 0.76 & 0.88 \\
\hline & $\mathrm{I}-200 \times 140 \times 14 \times 8.4$ & 0.72 & 0.83 & 0.83 \\
\hline & $\mathrm{I}-200 \times 140 \times 16 \times 9.6$ & 0.83 & 0.83 & 0.88 \\
\hline & $\mathrm{I}-200 \times 140 \times 18 \times 10.8$ & 0.83 & 0.83 & 0.92 \\
\hline \multirow{4}{*}{ 3-point bending tests } & $\mathrm{I}-200 \times 140 \times 6 \times 6-1$ & 0.72 & 0.76 & - \\
\hline & $\mathrm{I}-200 \times 140 \times 8 \times 6-1$ & 0.69 & 0.70 & 0.78 \\
\hline & $\mathrm{I}-200 \times 140 \times 10 \times 8-1$ & 0.69 & 0.69 & 0.75 \\
\hline & $\mathrm{I}-200 \times 140 \times 12 \times 8-1$ & 0.69 & 0.69 & 0.83 \\
\hline \multirow{14}{*}{$\begin{array}{l}\text { 3-point bending FE } \\
\text { models }\end{array}$} & $\mathrm{I}-200 \times 140 \times 4 \times 2.4-1$ & 0.91 & 0.97 & - \\
\hline & $\mathrm{I}-200 \times 140 \times 5 \times 3-1$ & 0.90 & 0.90 & - \\
\hline & $\mathrm{I}-200 \times 140 \times 6 \times 3.6-1$ & 0.65 & 0.75 & - \\
\hline & $\mathrm{I}-200 \times 140 \times 8 \times 4.8-1$ & 0.70 & 0.78 & 0.85 \\
\hline & $\mathrm{I}-200 \times 140 \times 9 \times 5.4-1$ & 0.75 & 0.75 & 0.84 \\
\hline & $\mathrm{I}-200 \times 140 \times 12 \times 7.2-1$ & 0.79 & 0.79 & 0.91 \\
\hline & $\mathrm{I}-200 \times 140 \times 14 \times 8.4-1$ & 0.79 & 0.79 & 0.99 \\
\hline & $\mathrm{I}-200 \times 140 \times 16 \times 9.6-1$ & 0.78 & 0.78 & 0.99 \\
\hline & I- $200 \times 140 \times 6 \times 2.4-1$ & 0.75 & 0.86 & - \\
\hline & $\mathrm{I}-200 \times 140 \times 8 \times 3.2-1$ & 0.75 & 0.76 & 0.87 \\
\hline & $\mathrm{I}-200 \times 140 \times 10 \times 4-1$ & 0.77 & 0.77 & 0.88 \\
\hline & $\mathrm{I}-200 \times 140 \times 12 \times 4.8-1$ & 0.82 & 0.82 & 0.93 \\
\hline & $\mathrm{I}-200 \times 140 \times 16 \times 6.4-1$ & 0.81 & 0.81 & 1.04 \\
\hline & $\mathrm{I}-200 \times 140 \times 20 \times 6.4-1$ & 0.82 & 0.82 & 1.05 \\
\hline \multirow{4}{*}{ 4-point bending tests } & $\mathrm{I}-200 \times 140 \times 6 \times 6-2$ & 0.73 & 0.77 & - \\
\hline & $\mathrm{I}-200 \times 140 \times 8 \times 6-2$ & 0.79 & 0.81 & 0.90 \\
\hline & $\mathrm{I}-200 \times 140 \times 10 \times 8-2$ & 0.85 & 0.85 & 0.92 \\
\hline & $\mathrm{I}-200 \times 140 \times 12 \times 8-2$ & 0.80 & 0.80 & 0.95 \\
\hline \multirow{14}{*}{$\begin{array}{l}\text { 4-point bending FE } \\
\text { models }\end{array}$} & $\mathrm{I}-200 \times 140 \times 4 \times 2.4-2$ & 1.01 & 1.08 & - \\
\hline & $\mathrm{I}-200 \times 140 \times 5 \times 3-2$ & 1.04 & 1.04 & - \\
\hline & I- $200 \times 140 \times 6 \times 3.6-2$ & 0.75 & 0.86 & - \\
\hline & $\mathrm{I}-200 \times 140 \times 8 \times 4.8-2$ & 0.77 & 0.86 & 0.93 \\
\hline & $\mathrm{I}-200 \times 140 \times 9 \times 5.4-2$ & 0.82 & 0.82 & 0.92 \\
\hline & $\mathrm{I}-200 \times 140 \times 12 \times 7.2-2$ & 0.85 & 0.85 & 0.98 \\
\hline & $\mathrm{I}-200 \times 140 \times 14 \times 8.4-2$ & 0.87 & 0.87 & 1.10 \\
\hline & $\mathrm{I}-200 \times 140 \times 16 \times 9.6-2$ & 0.87 & 0.87 & 1.10 \\
\hline & $\mathrm{I}-200 \times 140 \times 6 \times 2.4-2$ & 0.85 & 0.98 & - \\
\hline & I- $200 \times 140 \times 8 \times 3.2-2$ & 0.78 & 0.79 & 0.90 \\
\hline & $\mathrm{I}-200 \times 140 \times 10 \times 4-2$ & 0.87 & 0.87 & 0.99 \\
\hline & $\mathrm{I}-200 \times 140 \times 12 \times 4.8-2$ & 0.86 & 0.86 & 0.98 \\
\hline & $\mathrm{I}-200 \times 140 \times 16 \times 6.4-2$ & 0.82 & 0.82 & 1.05 \\
\hline & $\mathrm{I}-200 \times 140 \times 20 \times 6.4-2$ & 0.81 & 0.81 & 1.03 \\
\hline
\end{tabular}




\begin{tabular}{|c|c|c|c|c|} 
Mean & & 0.81 & 0.83 & 0.93 \\
\hline COV & & 0.097 & 0.095 & 0.093 \\
\hline
\end{tabular}

